\title{
La Derecha Liberal Republicana: un modelo de organización de un partido republicano conservador durante la Segunda República española
}

\author{
LUIS ÍNIIGO FERNÁNDEZ
}

\begin{abstract}
RESUMEN
La Derecha Liberal Republicana fue fundada en julio de 1930 por Niceto

Alcalá-Zamora y Miguel Maura

Gamazo. Su intención era la de incorporar a la República en ciernes a las fuerzas sociales conservadoras temerosas del desorden que podía suceder a la inminente caída de la Monarquía, y parecia ser una fuerza política a medio camino entre los partidos de cuadros tradicionales y los modernos partidos de masas. En apariencia capaz de encuadrar a gran número de afiliados, exigirles un fuerte

grado de compromiso, financiarse mediante sus aportaciones y orientar su acción en función de sus decisiones, no pasaba de ser en la práctica un entramado oligárquico en

el que lideres indiscutibles hacian prevalecer sus opiniones, sostenian las finanzas del partido y le imponian alianzas y enemistades casi siempre puramente personales. Tal contradicción, sumada a la especial

\section{ABSTRACT}

Niceto Alcalá-Zamora and Miguel Maura Gamazo founded the Derecha Liberal Republicana in July 1930. Its purpose was to add to the coming Republic the conservative social forces afraid of the civil disorders which could possible take place after the imminent fall of the Monarchy, and it seemed to be a political force between traditional staft parties and modern mass parties. Apparently, it was able to encompass a great number of subsidiaries, demanding of them a high degree of engagement, to finance the party with their fees and guide its action by their decisions. However, in fact, it was simply an oligarchic framework where unquestionable leaders imposed their opinions, supported finances and forced the party to alliances and enmities completely personal in most of cases. This contradiction, added to the special hardness of the
\end{abstract}


dificultad de la coyuntura histórica en la que se vio obligada a actuar, explica en buena medida la evolución y el trágico destino final de la $D L R$.

PALABRAS CLAVE Politica, Segunda República, partidos republicanos, derecha, organización, militantes, financiación, bases sociales, implantación geográfica, apoyo electoral, evolución. historical moment in which the party was forced to act, explains to a high extent the evolution and tragic destiny of the DLR.

\section{KEY WORDS}

Politics, Second Republic, Republican parties, right, organisation, militants, finances, social basis, geographic implantation, electoral support, evolution.

\section{INTRODUCCIÓN}

Un partido político moderno es, por encima de todo, una organización, y como tal debe ser abordado su estudio. No obstante, las primeras reflexiones teóricas sobre el tema apenas prestaron atención a este hecho. Antes del siglo $x \mid x$ se distinguía muy poco entre los partidos y las tradicionales facciones entregadas a la defensa de intereses particulares. Ello permitió a Lord Halifax, por ejemplo, sostener sin rubor en el siglo XVII que el mejor de los partidos políticos no era otra cosa que una suerte de conspiración contra el resto del país ', y no obedecen a una razón muy distinta las desconfianzas mostradas una centuria después por teóricos como Hume o Bolingbroke. Sólo superadas aquéllas fue decantándose un concepto liberal de partido que, en palabras del padre del liberalismo conservador, Edmun Burke, venía a considerarlo como «...un cuerpo de cuerpo de hombres unidos para promover, mediante su labor conjunta, el interés nacional sobre la base de algún principio particular acerca del cual todos están de acuerdo"?

Aunque la visión de Burke suponía un avance indiscutible, contenía, no obstante, alguna dosis de ingenuidad. Se trataba, como puede apreciarse, de una concepción en exceso finalista del partido - prejuicio teleológico la ha denominado Angelo Panebianco ${ }^{3}$ - que hacía de él poco más que un mero vehículo al servicio de una ideología, obviando cualquier otra consideración. Una concepción que, válida quizá para los par-

"The best party is but a kind of conspiracy against the rest of the nation", Works,

2 Cita extraida de Thoughts on the cause of the Present Discontent (1770), en SARTORI, Giovanni: Partidos y sistemas de partidos. Madrid, Alianza Editorial, 1994, p. 26.

3 Panebianco, Angelo: Modelos de partido. Madrid, Alianza Editorial, 1990, pp. 30-31 
tidos parlamentarios burgueses de la primera mitad del $\mathrm{XIX}{ }^{4}$, organizativamente débiles y discontinuos, habrían de irse corrigiendo a lo largo del siglo, a la par que la política iba dejando de ser negocio privado de un número restringido de notables para convertirse en asunto de unas masas que adquirían de forma paulatina su poder y con las que forzosamente habia que contar.

Ampliado el sufragio a toda la población masculina mayor de edad, los partidos ya no representan opciones de política práctica, diferencias de opinión tan sólo, en el seno de la misma clase social, sino que pasan a ser ellos mismos opciones de clase ${ }^{5}$. El proceso, que se inició fuera del parlamento con la aparición de los partidos socialistas, acabó por arrastrar a los viejos conglomerados burgueses de diputados y comités electorales, forzándolos a dotarse de una estructura más permanente y centralizada que va a merecer por fin la denominación de partido moderno. Para éste, que se mueve en el nuevo contexto de la democracia construída sobre la base del sufragio universal, cobra interés prioritario la captación del mayor número posible de votos, de cuyo volumen dependerá su peso parlamentario y sus opciones de acceder al poder o de condicionar su ejercicio por parte de otros, lo que constituye, en última instancia, la finalidad última de todo partido ${ }^{6}$. Ello le lleva a convertirse en una gran maquinaria electoral organizada con creciente perfección, mientras los fines ideológicos ceden con facilidad su anterior preeminencia ante todo lo que signifique la consolidación y el fortalecimiento de la organización, que ha terminado de este modo por convertirse ella misma en un fin cuyas necesidades e intereses tienden a imponerse sobre cualquier otro.

Una reflexión similar a éste llevó a comienzos de este siglo a Robert Michels a sostener que el exceso de organización conducía de forma inexorable al desarrollo de una tendencia hacia la oligarquia en el seno

4 Para el concepto de partido parlamentario, véase Duverger, Maurice: Los partidos políticos, México D.F., F.C.E., 1994, pp. 16 y ss. Puede consultarse también Martínez Sospedra, Manuel: Introducción a los partidos políticos, Barcelona, Ariel, 1996, p. 28. La tipología de partidos que ofrece este autor sorprende por su exhaustividad.

5 CRuz VILlalón, P.: "Teoria e ideología del partido politico", en DE VEGA, P. (Ed.): Teoría y práctica de los partidos políticos, Madrid, Edicusa, 1977, pp. 29-41

6 Aunque no todos los estudiosos de los partidos están de acuerdo en este punto (véase, por ejemplo, PanebIanco, Ángelo.: Modelos..., p. 32), la gran mayoría coinciden en señalar que uno de los rasgos que mejor distingue al partido de otras organizaciones politicas como las ligas o los grupos de presión es su voluntad inequívoca de conquistar y ejercer el poder. Una selección de las definiciones más importantes que se han dado del partido puede encontrarse en SARTONI, Giovanni: Partidos..., p. 82 y ss. 
de los partidos ${ }^{7}$. Y ya en nuestros días ha servido de base al citado Angelo Panebianco para enunciar su conocida tesis, en virtud de la cual los partidos son, ante todo, organizaciones, y en cuanto tales, «...cualesquiera que sean las actividades que desarrollan y los beneficios o perjuicios que procuran a los hombres, invariablemente todas ellas sirven también para garantizar, perpetuar o acrecentar el poder de aquellos que las controlan" ${ }^{8}$.

Por supuesto, es posible discrepar de esa conclusión, pero lo que no cabe negar ya en el estadio evolutivo actual de la politología es la imposibilidad de abordar el estudio de la forma en que un partido desempeña su papel en el escenario de la lucha política si se le considera tan sólo el instrumento de que viene a dotarse un conjunto más o menos articulado de ideas para encarnarse en un programa práctico de gobierno o de oposición. No lo entenderemos nunca, por supuesto, si nos limitamos a narrar su simple trayectoria biológica. Ni tampoco, dando un paso más, es suficiente con tener presente las funciones de expresión y canalización de los intereses sociales que desempeñan los partidos ${ }^{9}$ o reconocer en ellos las formas de socialización que señalará Max Weber ${ }^{10}$. Los desequilibrios, las tensiones, los intereses y, en fin, la dinámica misma que genera la organización no pueden despreciarse nunca por completo como factores explicativos, dentro, por supuesto, de un contexto pluricausal que ha de tener en cuenta todos los aspectos señalados, así como las interactuaciones entre ellos, a la hora de intentar comprender cómo se desarrolla la vida de los partidos.

No obstante, siendo esto cierto, no lo es por igual para todos los partidos en todas las épocas. No puede serlo, porque el desarrollo de la

"La organización - recalca Michels - implica la tendencia a la oligarquía" (MicHELS, Robert: Los partidos politicos, Un estudio sociológico de las tendencias oligárquicas de la democracia moderna. Buenos Aires, Amorrortu, 1991 (dos vols.), volumen I, p. 77. La obra data, como es sabido, de 1915).

8 Panebianco, Angelo: Modelos..., p. 16. Una buena sistesis de la tesis de Panebianco puede encontrarse en ARRANZ, Luis: "Modelos de partido", en Juliá, Santos (ed): Politica en la segunda República, Ayer, n. ${ }^{\circ} 20,1995$, pp. 81 y ss.

- SaRtori, Giovanni.: Partidos..., pp. 56 y ss.

10 VID Weber, Max: “Tipos y estructuras de partidos", en LENK, K. Y NeUmanN, F.(eds): Teoría y sociologia críticas de los partidos políticos, Barcelona, Anagrama, 1980, pp. 299-313. Como puede imaginarse, no se trata de un articulo de Weber escrito para esta obra sino de un fragmento de su trabajo de 1922 Wirstschaft und Gesellschaft, en la definia a los partidos como "...las formas de socialización que descansando en un reclutamiento (formalmente) libre, tienen como fin proporcionar poder a sus dirigentes dentro de una asociación y otorgar por ese medio a sus miembros activos determinadas posibilidades ideales o materiales (la realización de fines objetivos o el logro de ventajas personales o ambas cosas)" ( $p .299)$ 
organización no ha alcanzado el mismo nivel en todos ellos y, en consecuencia, sus intereses y fines no pueden tener el mismo peso específico sobre la marcha del partido. Hasta qué punto esto es así para cada uno de los que operaban en la España de la Segunda República y cuál es, en consecuencia, su grado de madurez organizativa, es algo que se ha ido desentrañando, con mayor o menor profundidad en cada caso, en las monografías que se han ocupado de la mayoría de ellos. El objetivo de este trabajo es, precisamente, dilucidar en qué punto exacto del largo camino que va de los partidos burgueses de cuadros a los grandes partidos de masas se encontraba el grupo político conocido como Derecha Liberal Republicana, ya que este partido, a pesar de su importancia durante los primeros meses de la Segunda República, en los que contó con dos ministros en el Gobierno -Niceto Alcalá-Zamora, su presidente, y el ministro de la Gobernación, Miguel Maura- y de su destacada presencia en el mismo en el transcurso del segundo bienio del régimen, no ha sido objeto hasta la fecha de una monografía comparable a la que han merecido la práctica totalidad de las demás fuerzas políticas republicanas ${ }^{11}$.

Antes es necesario, sin embargo, recordar, siquiera con brevedad, la historia del partido que nos ocupa y ver qué se ha dicho hasta ahora sobre él en lo referente a organización. Sus raíces más remotas hay que buscarlas en la Dictadura de Miguel Primo de Rivera, en cuyo origen y dilatada supervivencia atribuyeron un papel fundamental al rey Alfonso XIII algunos políticos que hasta entonces militaban en las filas de los partidos dinásticos. Entre ellos se encontraban, a la sazón, Niceto Alcalá Zamora, jefe de una de las facciones del partido liberal y dos veces ministro antes de 1923, y Miguel Maura, hijo del que fuera caudillo conservador Antonio Maura y diputado por el distrito alicantino de Pego en las últimas Cortes de la Monarquía. En distinto momento, y motivados ambos por el desprecio que les mereció la actitud del monarca, que consideraban una traición a la Constitución, y por el convencimiento creciente de que la caída de la Dictadura habria de dejar paso de manera inevitable a la República, pues las únicas fuerzas políticas organizadas que quedaban en España eran las republicanas y obreras, terminaron por convenir en la necesidad de que los conservadores españoles se sumaran al nuevo régimen

\footnotetext{
Sólo el artículo, el publicado por Juan AVILÉs hace ya más de veinte años ( «La derecha republicana: 1930-1936", Revista de estudios sociales, n. ${ }^{\circ}$ 16, enero-abril de 1976, pp. 77-117) se ha ocupado con alguna profundidad de la DLR, aunque no exclusiva, ya que este trabajo se ocupa también del Partido Republicano Conservador, fundado por Miguel Maura tras su abandono del partido en 1931 .
} 
para evitar que se desviara hacia posiciones radicales que pusieran en peligro sus intereses de clase ${ }^{12}$.

Tal fue la causa última de la fundación, en julio de 1930, de la Derecha Liberal Republicana, que vió la luz tras dos reuniones celebradas en Madrid los días 5 y 7 de dicho mes. En la primera de ellas, todavía sin la presencia de don Niceto, un grupo de amigos suyos decidieron proceder a la fundación oficial del partido, forzada en cierto modo por la proliferación en amplias zonas del pais de agrupaciones políticas locales que proclaman su acuerdo con las posturas expresadas por el ilustre prieguense en su discurso del teatro Apolo de Valencia ${ }^{13}$. También quedó ya definido en dicha reunión el principal objetivo del partido - agrupar dentro de la República a las fuerzas conservadoras españolas - así como otras cuestiones de índole más práctica, como el alquiler de un piso que sirviera de domicilio social a la Secretaría Central y la aprobación de cuotas destinadas a sufragar los gastos derivados de dicha operación ${ }^{14}$. En la Segunda reunión, celebrada ya bajo la presidencia de Alcalá-Zamora y con asistencia de Miguel Maura, se decidió, parece que por la gran insistencia que en ello puso éste último, dar al partido el nombre de Derecha Liberal Republicana ${ }^{15}$ y fueron aprobadas las líneas generales del manifiesto que se acordó dirigir al país en fecha próxima.

12 "...el incendio - decía AlCalA-Zamora en el teatro Apolo de Valencia el 13 de abril de 1930 , en el discurso en que al fin proclamaba oficialmente su republicanismo- es lava avasalladora que se nos viene encima, por eso, porque es lava que desde la altura desciende y amenaza arrasar la libertad y la existencia de la patria, tenemos el deber, o de que el volcán quede extinto, o de traspasar nuestros hogares o nuestros pueblos a ambientes más benignos, a otras instituciones en que puedan vivir nuestros hijos" (ALCALA-ZAMORA, Niceto: Discursos. Madrid, Tecnos, 1979, p. 485).

13 Una buena fuente de información sobre la aparicion de estas agrupaciones locales es el seminario Democracia, afín al nicetismo, que se publicó en la ciudad alicantina de Alcoy entre el 1 de marzo de 1930 y el 11 de julio de 1931. Por desgracia, parece que este periódico sólo puede consultarse en la Biblioteca Pública de dicha localidad en condiciones un tanto incómodas.

14 El acta de esta reunión puede consultarse en el Archivo Histórico Nacional, Sección Guerra Civil, en Salamanca (en adelante AHNS), Sección Político-Social, Madrid, carpeta 630, legajo 873. Una síntesis de 10 tratado los dias 5 y 7 de julio, en AvLÉS, Juan: "La derecha...", pp. 70 80, y en Álvarez ReY, L.: “El proyecto político de Alcalá-Zamora y Torres (ed.): II Jornadas Niceto Alcalá-Zamora y su época. Priego de Córdoba, 1997, pp. 39-40

15 AHNS, Político-Social, Madrid, carpeta 630, legajo 873. De acuerdo con el testimonio de don Niceto, Maura deseaba dejar muy claro el carácter conservador de la nueva fuerza política. En su mente, la palabra Derecha era lo sustantivo mientras el apelativo Liberal que la acompañaba tan sólo lo adjetivo, que Maura habia consetido en incluir como una concesión honorífica al futuro presidente de la República. Si de éste hubiera dependido, el partido se habría llamado desde el principio Republicano Progresista, nombre que adoptaria en su primera asamblea Nacional, en agosto de 1931, cuando ya Maura lo había abandonado de facto (ALCALA-ZAMORA, Niceto: Memorias. Barcelona, Planeta, 1977, p. 134). 
Dicho manifiesto apareció una semana después, el 14 de julio de 1930, bajo el título de Carta Circular de la Derecha Liberal Republicana ${ }^{16}$. En él se trazaban ya las líneas básicas del ideario y del programa mismo del partido, que se proclamaba decididamente republicano y centrista por vocación, aunque consciente de hallarse a la derecha de las fuerzas que se calaban el gorro frigio, a la vez que definía un Estado ideal edificado sobre los principios del liberalismo democrático, el orden y la autoridad y la autonomía regional dentro de la unidad de la Nación española. Semanas después, se sumaban Alcalá-Zamora y Miguel Maura a los preparativos para la reunión de las fuerzas republicanas que, celebrada en San Sebastian el día 17 de agosto, dio lugar al célebre pacto por el que los presentes acordaron la preparación del movimiento que habría de derribar la Monarquía. Decidida también la formación de un Comité revolucionario, que con el tiempo había de convertirse en el primer Gobierno provisional de la República, fue el mismo Alcalá-Zamora el designado para presidirlo, quedando también integrado en él Miguel Maura.

Presentada ya la fuerza política objeto de este trabajo, parece imprescindible definir cuál es en este momento el estado de la cuestión, o, en otras palabras, recordar to dicho hasta ahora sobre el problema que nos ocupa: el grado de madurez que llega a alcanzar su organización como partido. La prensa comtemporánea, paradójicamente, se ocupa ya de algún modo del tema y llega a ofrecer de la Derecha Liberal Republicana una imagen que nos define una organización partido mucho menos próxima al partido de masas moderno que al modelo burgués tradicional de partido de cuadros, construidos sobre comités poco extensos, bastante independientes entre si, orientado más a la agrupación de notables que a la captación de un gran número de afiliados y animado por una escasa actividad fuera de los períodos electorales ${ }^{17}$. Un partido, incluso, que no ha llegado a serlo del todo, a pesar de las grandes esperanzas depositạdas en él por una buena parte de la opinión pública. Así, El Heraldo de Madrid decía de la DLR apenas un año después de su fundación que había sido "...un partido en potencia, una promesa de fortaleza en los días en que triunfó la República y $D$. Niceto asumía la presencia del Gobierno; fue la esperanza - continuaba- de la burguesía apolítica, que se aprestaba ia lanzarse a la lucha por primera vez", pero no quedaba ya de ella sino "...un núcleo fluctuante que busca techo", un

16 AHNS, Político-Social, Madrid, carpeta 625, legajo 869.

17 Una descripción del modelo en DuVerger, Maurice: Los partidos..., p. 31 
"grupito torvo" que acabaria por esfumarse sin dejar huella para dejar paso a la nueva derecha republicana que habría de ver la luz de la mano de Miguel Maura ${ }^{18}$.

Los historiadores, por su parte, parecen haber confirmado esta imagen. Javier Tusell ${ }^{19}$, por ejemplo, caracteriza a la DLR como un grupo político desorganizado, fuertemente dependiente de las redes de influencia caciquil en manos de algunos de sus líderes, poco disciplinado y carente de vertebración. Y Juan Avilés, el único, como hemos dicho, en dedicar a la DLR una cierta atención, concluye su artículo afirmando que tanto este partido como el Republicano Conservador, fundado después por Maura, «...eran claramente partidos de notables", aunque «...adoptaron, al menos en apariencia, algunas de las características propias de los modernos partidos de masas: el encuadramiento de gran número de afiliados, la financiación mediante las cuotas pagadas por estos, la celebración de asambleas nacionales, que constituían el órgano soberano del partido...»20.

¿Debe darse por cierta esta imagen? Las fuentes con que contamos para averiguarlo no son abundantes en exceso, pero tampoco insuficientes. La documentación interna de carácter estatutario, por ejemplo, es bastante rica. En el Fondo Comín Colomer, depositado en la Biblioteca Nacional, se encuentran un ejemplar de los Estatutos del Partido Republicano Progresista y el Modelo de Reglamento para el funcionamiento de sus agrupaciones locales. En Salamanca, en la Sección Guerra Civil del Archivo Histórico Nacional, se hallan también algunos ejemplares concretos de Reglamentos de Comités locales y provinciales del partido, asi como varios miles de boletines y fichas de afiliación que contienen jugosos datos sobre fechas, profesiones y cuotas satisfechas por los militantes, y también actas, circulares y otros documentos internos de carácter oficial que recogen las actividades cotidianas de distintos organismos, entre ellos el Comité Ejecutivo y la Asamblea Nacional. No menos importante ha sido la posibilidad de consultar abundante correspondencia oficial, y en menor medida, privada, entre la Secretaría Central de Madrid y algunos de los prohombres progresistas en las distintas provincias, 0 entre estos últimos, lo que nos abre un interesante panorama de las verdaderas relaciones de poder en el seno del progresismo, ofreciendo de él

18 «El partido sin nombre y sin jefe», Heraldo de Madrid, 29 de julio de 1931.

19 TUSELL, Javier: Las constituyentes de 1931: unas elecciones de transición. Madrid, CIS, 1982, pp. 29 y ss.

20 AVILES, Juan: "La derecha...", p. 116 
una imagen mucho más real que la que cabría deducir de la simple lectura de sus reglamentos y circulares, pues sin duda acierta Panebianco cuando sostiene que el estudio de los estatutos de un partido puede trazar una imagen de él por completo alejada de la realidad ${ }^{21}$.

En este sentido, resulta no menos útil la consulta de la documentación de carácter memorial conservada. Por fortuna, no son pocos los líderes de la Derecha Liberal Republicana que nos han dejado un testimonio escrito de sus actividades políticas. El mismo Alcalá-Zamora, como es bien sabido, redactó unas memorias que han sido objeto no hace mucho de una reedición. También ricos en información resultan los recuerdos de personajes quizá más secundarios pero sin duda más próximos a la vida de un partido que don Niceto, al menos en apariencia, abandonó muy pronto para ascender a la Presidencia de la República. Así, Rafael Sánchez Guerra, Juan Castrillo Santos o Luis Recasens nos han dejado obras que, en ocasiones, descienden a detalles que resultan de mucho interés para comprender cómo se desarrollaba, más allá de la letra de los Estatutos, la vida real del progresismo republicano.

Por último, la prensa no podía dejar de aportar una valiosa información, tanto más cuando, como en este caso, contamos con periódicos de partido que, aunque no disfrutaron nunca de gran difusión ni tampoco alcanzaron una duración importante, resultan de mucha utilidad para satisfacer la finalidad que aquí nos interesa: proporcionar información acerca de la vida interna del progresismo, sobre todo en su dimensión local. Así, periódicos como el semanario alcoyano Democracia, dotado de una tirada que debió de ser mínima, una extensión exigua y una duración que no pasó de unos meses, ofrece una imagen muy nítida de lo que debía de ser la actividad habitual de las agrupaciones locales del partido, y lo mismo podría decirse de El Correo, diario alicantino que simpatizó con la DLR entre mayo y agosto de 1931, hasta que las expectativas políticas de su director, Florentino de Elizaicín, que aspiraba a un escaño de diputado por la provincia levantina, quedaron frustradas, o del rotativo madrileño La Defensa, que fue progresista tan sólo durante unas semanas a mediados de 1933. Periódico de gran formato, tan pobre en páginas como en calidad, aporta sin embargo, datos fundamentales sobre la activididad del partido en la capital de España. Por último, simpatías

21 "Los estatutos de un partido - señala el autor italiano- no describen su organización, del mismo modo que una constitución no describe la fisonomía de un sistema político. Los estatutos son tan sólo una pálida huella, enormemente lábil e imprecisa; poco más que un punto de partida en el análisis organizativo de un partido político" (PANEBIANCO, Angelo: Modelos..., p. 87). 
como las expresadas por periódicos de mayor peso y prestigio, como los diarios madrileños Ahora y Crisol, serán o compartidas con el conjunto de las fuerzas republicanas templadas, como en el primer caso, o poco duraderas, como en el segundo.

\section{LA ORGANIZACIÓN LOCAL Y PROVINCIAL}

La estructura general de la Derecha Liberal Republicana, luego Partido Republicano Progresista, quedó ya definida en una carta que remitía en fecha tan temprana como el 26 de agosto de 1930 su Secretaría central al secretario de un Comité local que, como tantos otros por entonces, se habia dirigido a ella para darle cuenta de su costitución y solicitarle instrucciones ${ }^{22}$. Aunque en la contestación se señala que la información que contiene es más bien orientativa, ya que su validez está condicionada, como no podía ser de otro modo, a lo que se apruebe en la primera Asamblea Nacional del partido, cuya celebración se esperaba por entonces para el mes de octubre, sabemos que en sus grandes líneas la DLRPRP respondió a este modelo.

La carta diseñaba un entramado organizativo fiel en esencia a lo que había sido la norma de los partidos republicanos, aunque matizada por un claro deseo de adaptación democratica a los nuevos tiempos, marcados por una creciente participación política de la población, fenómeno que imponia, al menos en teoría, la necesidad de introducir mecanismos de integración y movilización de un importante volumen de simpatizantes y afiliados. La célula básica era el Comité municipal, que en las localidades en las que el volumen de afiliados asi lo aconsejara, podía estar articulado en Comités de distrito. Por encima de aquéllos, los Comités provinciales y regionales - planteados los últimos tan sólo como posibilidad-coordinarían la labor de sus homónimos locales y servirian de intermediarios, aunque no en todas las actividades, entre estos y la organización central del partido, encarnada en un órgano permanente de carácter burocrático, la Secretaria central, afecto a otro de índole política, el Comité Nacional, que lo gobernaría siguiendo las pautas marcadas por las Asambleas nacionales anuales.

Veamos con un poco más de detalle esta descripción general. Como acabamos de observar, en la base de la organización de la DLR se encontraba el Comité municipal, pero no era ésta, como acaso pudiera pensarse,

22 AMNS, Político-Social, Madrid, carpeta 625, legajo 869. 
la más pequeña de las estructuras en que se asentaba la organización progresista, ya que dicho Comité procuraba adaptarse a la variopinta estructura de poblamiento que podemos encontrar en las distintas regiones. Así, en las ciudades medianas y grandes, divididas en distritos, por debajo de los Comités municipales suelen aparecer Comités de distrito o Subcomités, que en el caso de términos municipales compuestos por diversos núcleos de población, como es frecuente en el Norte de España, residian en cada uno de ellos. Por tratarse de un partido democrático, y el que nos ocupa proclama serlo, sería de esperar que los delegados de estos subcomités, elegidos en le número y la forma que determinasen los estatutos, constituyeran el Comité municipal. Así lo establecen los Estatutos del PRP, aunque se limitan a decir que "Las organizaciones primarias de distrito municipal [...] podrán crear Juntas municipales de conjunto, elegidas y reglamentadas por delegados de los Comités de Distrito" ${ }^{23}$. Una circular enviada por la Secretaría central del partido a los presidentes de los Comités de distrito de Madrid el 21 de diciembre de 1931 les informaba de la próxima constitución del Comité municipal, que estaría integrado por dos delegados de cada distrito, lo que hacia un total de veinte, que habrian de elegir después de entre ellos un presidente al que se le concedería el voto de calidad para deshacer desempates ${ }^{24}$. Ignoramos, sin embargo, si todos los Comités seguian con precisión esta pauta, pues nada se dice al respecto en el modelo de Reglamento de las agrupaciones municipales, pero podemos suponer que no, puesto que ni siquiera se mantuvo mucho tiempo sin cambios en el caso de Madrid. En un documento sin fecha que creemos correspondiente a la segunda Asamblea Nacional del Partido Republicano Progresista ya no hay sino un delegado por distrito, $y$ aparece ademas otro que no corresponde a ninguno de ellos ${ }^{25}$. En otros casos, como, por ejemplo, el de Melilla, parece que el sentido de la elección se invertía, pues era el Comité municipal el que controlaba la elección de los presidentes de los comités de distrito e incluso todas sus actividades, hasta el punto de dejarles privados de la más minima autonomía ${ }^{26}$. De estos ejemplos cabe deducir que los ór-

${ }^{23}$ Partido Republicano Progresista. Estatutos y anexos. Biblioteca Nacional, Madrid (en adelante BNM), Fondo Comin Colomer, sign.3/103.087.

24 AHNS, Político-Social, Madrid, carpeta 630, legajo 873. El mecanismo queda confirmado por una noticia aparecida en el periódico madrileño El Sol el 29 de enero de 1932 en la que se nos informa que el Comité del distrito de La Inclusa habia elegido "...para representar a este Comité en la Junta municipal a D. Isidoro Gallo y a D. Fernando Santamaría...".

25. AHNS, Político-Social, Madrid, carpeta 1897. Creemos que pertenece a la segunda Asamblea del partido (febrero-marzo de 1932) por haber encontrado el documento entre los correspondientes a dicha Asamblea.

26 Acta del Comité de Melilla, 11 de octubre de 1933. AHNS, Político-Social, Madrid, carpeta 627 , legajo 870 . Se dice textuaimente que habrán de «...dar cuenta de todos sus actos al Co- 
ganos centrales del partido concedían una gran libertad a las agrupaciones locales para su organización interna, aunque, como vemos, en ocasiones esto significara atentar contra los principios democráticos en que decia inspirarse la DLR. Había, eso sí, modelos de Reglamento para los comités locales, incluso de varios tipos ${ }^{27}$, pero por lo que parece éstos no se imponían, sino que desempeñaban tan sólo el papel de una orientación que los comités podian seguir en mayor o menor grado, lo que explicaría diferencias como las que acabamos de exponer. En todo caso, parece que el ejemplo de Melilla era poco habitual en la DLR, quizá porque los Comités de barrio o distrito nacieron en la ciudad norteafricana mucho después que el municipal. Lo má frecuente era componer los Comités municipales mediante delegados de los Subcomités allí donde los hubiere o bien que estos delegados, reunidos en pleno, eligieran después el Comité municipal. El hecho de que en las Asambleas Nacionales los Comités de distrito madrileños estuvieran representados con voz y voto ${ }^{28}$ abona la impresión de que el comité progresista de Melilla constituía una excepción más que la regla. Pero, siendo esto así, no es posible desterrar por completo la impresión de una cierta desorganización y un funcionamiento poco eficaz de la estructura del progresismo en sus niveles más bajos.

También variaba de modo considerable, por lo que parece, la composición de la Junta Directiva de los Comités, tanto municipales como de distrito. Lo más habitual es la presencia de uno o varios presidentes honorarios, escogidos entre las figuras más destacadas del partido a nivel nacional o regional, prueba evidente de que los militantes tendian a identificarse más con un persona determinada que con las siglas, y de la existencia, en muchos casos, de una red de influencias más o menos personales a menudo preexistentes a la fundación de la DLR y cuya simple yuxtaposición va a venir en buena medida a constituir el partido

mité local antes de efectuar cualquier reunión, para recabar la oportuna autorización". Por el contrario el Reglamento del Comité de Chamberi proclama en su artículo 2. la autonomía del mismo en todo lo que no se refiera a aspectos relacionados con la ideología, el programa y la táctica política del partido (AHNS, Político-Social, Madrid, carpeta 630, legajo 873).

27 El semanario politico Democracia, de Alcoy, uno de los pocos órganos de prensa afine con los que contó el progresismo, decia el 25 de octubre de 1930 que Niceto ALCALÁ-ZamORA, durante su estancia en la ciudad alicantina, "Pidió y se trajo de Jávea uno de los dos modelos de reglamento que a disposición de los comités de la provincia tienen allí (...) Nuestro jefe provincial tiene redactados dos modelos de Reglamento, uno para los pueblos pequeños y otro para las poblaciones de más de 4000 almas». Parece, por tanto, que existían otros modelos de Reglamento además del que hemos hallado en la Biblioteca Nacional de Madrid y que los Comités tenian cierta libertad para escoger uno $u$ otro e incluso modificarlo.

28 Circular enviada por la Secretaría central del PRP a los presidentes de los Comités de distrito de Madrid, 21 de diciembre de 1931. AHNS, Político-Social, Madrid, carpeta 630, legajo 873. 
mismo. Junto a esta presidencia honoraria, sin función ni presencia alguna, pero de significación tan elocuente, encontramos un presidente efectivo, uno o varios vicepresidentes, secretario, tesorero y cierto número de vocales, que pueden oscilar entre sólo tres y más de diez. Además estos cargos, algunos de los cuales se duplican en ocasiones, pueden aparecer otros menos frecuentes, como el contador o el bibliotecario, $e$ incluso vocales natos, que acceden al puesto como consecuencia del desempeño de cargos políticos en la administración municipal. Excepto en este caso, todos los miembros del Comité son elegidos periódicamente de acuerdo con normas que se establecen en los correspondientes Reglamentos, que llegan a ser bastante explícitos al respecto, lo que nos indica la existencia de unas ciertas garantías democráticas en el funcionamiento interno de los Comités ${ }^{29}$. La renovación de los cargos, que se desarrollaba por mitades, tenía carácter anual y tendía a producirse en el mes de diciembre ${ }^{30}$.

Además de la junta directiva, pero en directa dependencia de ella, podían constituirse comisiones con funciones específicas que estaban integradas en ocasiones exclusivamente por miembros de la directiva, pero a veces también por simples afiliados al partido sin otro cargo dentro de él. El Comité progresista de Chamberi, por ejemplo, prevé en el Artículo 19 de su Reglamento la existencia de una comisión electoral y otra de propaganda cuyos miembros «...podrán no pertenecer a la Junta directiva", si bien, sin duda para evitar una acción demasiado independiente de estas comisiones, se introduce una limitación: "Se designará asimismo para formar parte de ellas a un vocal de la propia Junta» ${ }^{31}$.

Era, pues, en estas estructuras, células elementales del tejido organizativo del progresismo, en las que se integraban sus afiliados de base, aunque sabemos que se permitía también la afiliación directa al Comité Nacional sin necesidad de integrarse en el local (art. 11 de los Estatutos). De ellos sabemos algunas cosas. Sus derechos y obligaciones, por

29 Los reglamento especifican, por ejemplo, las normas para el uso de la palabra en las asambleas o los procedimientos a seguir en las votaciones. Véase, por ejemplo Partido Republicano Progresista. Reglamento de las Agrupaciones municipales, Capítulo IV: "Comité directivo" (BNM, Fondo Comín Colomer, sign. 3/104.951).

30 Partido Republicano Progresista. Reglamento de las Agrupaciones Municipales,artículo 18 (BNM, Fondo Comín Colomer, sign. 3/104.951); Reglamento del Partido Republicano Progresista de Melilla. 1932, Articulo 35 (AHNS, Político-Social, Madrid, carpeta 625. legajo, 689); Reglamento del Partido Republicano Progresista. Comité de Chamberi, Luchana n. ${ }^{\circ}$ 20, Madrid, Artículo 15. (AHNS, Político-Social, Madrid, carpeta 630, legajo, 873).

31 Reglamento del Partido...AHNS, Político-Social, Madrid, carpeta 630, legajo, 873. 
ejemplo, son, en teoría al menos, muy similares a los que caracterizan a los afiliados de los grandes partidos de masas. Los Reglamentos que se han conservado no olvidan incluir ni uno sólo de los criterios que vienen usándose tradicionalmente para distinguir a estas nuevas formas de movilización política de los viejos partidos burgueses de cuadros ${ }^{32}$. Los aspirantes a ingresar en las filas progresistas debian ser presentados por dos afiliados, solicitarlo por escrito mediante un boletín de adhesión oficial y ser aceptados explícitamente por la junta directiva, imponiendo incluso algún comité un periodo de exposición de su nombre en sitio público durante un tiempo determinado para dar la oportunidad a los afiliados a oponerse a la admisión de manera fundada ${ }^{33}$. Las obligaciones que se imponian a los afiliados eran las habituales: aceptar el ideario del partido y acatar su disciplina, proveerse del carnet de afiliado y -no siempre - someterlo a un estampillado periódico, satisfacer una cuota mensual y cooperar en la realización de los fines del partido. Y lo mismo cabe decir de sus derechos: asistir a las juntas generales con voz y voto, ser elector y elegible para los cargos directivos (aunque casi siempre con limitaciones de antigüedad), y utilizar las instalaciones de que el partido pudiera dotarse. Algún comité como los de Melilla y Zaragoza, por ejemplo, llegan incluso a establecer una jerarquía de afiliación diferenciada por la calidad y cantidad de los derechos que se conceden a cada grupo que va mucho más allá de la sugerida en el modelo de Reglamento del partido ${ }^{34}$.

Pero no eran los comités municipales las únicas instituciones mediante las cuales el progresismo estaba presente en la vida de las comunidades locales. Dejando aparte la Sección Femenina y la Juventud, que constituian una red paralela a los Comités en todos los niveles de la organización, y que merecen un estudio más detallado que abordamos más adelante, existían también otros organismos municipales, relativamente autónomos, de gran tradición no ya sólo en el republicanismo histórico español, sino incluso en la vieja política en la era de los notables. Estos organismos municipales, que suelen tomar el nombre de Círculos, asumen determinadas funciones de carácter lúdico y cultural que, incluídas entre las propias de los comités locales, se desgloban de ellas para

32 Pueden verse estos criterios en Duvergen, Maurice: Los partidos..., pp. 93 y ss.

33 Reglamento del Partido Republicano Progresista. Melilla, 1932. Artículo 23. AHNS, PolíticoSocial, Madrid, carpeta 625, legajo, 689.

34 El modelo de Reglamento de las Agrupaciones municipales distinguía entre socios fundadores y socios de número (Reglamento de las Agrupaciones municipales..., Artículo 7. ${ }^{\circ}, \mathrm{BNM}$, Fondo Comín Colomer, 3/104.951). El Comité de Melilla, por su parte, llega a establecer hasta cuatro categorias de afiliados con distintos derechos. 
ser atribuidas a estas agrupaciones alli donde el volumen de la afiliación al partido o las necesidades de la población, pues no siempre dirigen sus actividades a afiliados o simpatizantes en exclusiva, aconsejan su creación.

El funcionamiento de estos organismos periféricos nos es bien conocido por haberse conservado el reglamento de uno de ellos: el Círculo de Zaragoza. Por lo que parece, jerárquicamente dependían de los Comités municipales ${ }^{35} \mathrm{y}$, compartiendo con ellos los que podríamos denominar altos ideales del partido al que pertenecen, dedicaban sus esfuerzos a actividades más mundanas y, desde luego, mucho más prácticas, como podían ser la beneficencia, la fundación de pequeños periódicos de difusión local, o la organización de veladas y actos culturales, sin excluir quehaceres más puramente lúdicos como los simples juegos, siempre «...que no se opongan a las leyes» ${ }^{36}$. Funciones éstas que, alli donde no se organizaran círculos, debían asumir también, como hemos dicho, los comités locales ordinarios, en el caso de que contaran con locales y medios para ello ${ }^{37}$. Debe destacarse, en todo caso, que la existencia de este tipo de instituciones, a pesar del escaso grado de penetración social que llegaron a conseguir, es de algún modo indicativa de una cierta modernidad en la concepción política del progresismo, pues nos está hablando de la presencia de mecanismo de captación y preservación de la afiliación característicos de los partidos de masas ${ }^{38}$. No debemos caer, no obstante, en la tentación de exagerar este aspecto moderno del

35 El Reglamento del Comité progresista de Melilla señala en su Artículo 11 la posibilidad de que se organicen "...otras agrupaciones menores dependientes del Comité directivo", especificándose que dichas agrupaciones son los círculos (Articulo 12) y las Juventudes y Sección Femenina (Articulo 15). De todos ellos dice taxativamente el Artículo 11 que su reglamentación estará «...ajustada en un todo al presente Reglamento y sin que puedan tener tal autonomía que las permitan obrar [sic] sin la aprobación del referido Comité directivo" (AHNS, Político-Social, Madrid, carpeta 625, legajo, 689).

36 Reglamento por el que ha de regirse el círculo de la Derecha Liberal Republicana, Zaragoza, 17 de marzo de 1931 (AHNS, Político-Social, Madrid, carpeta 625, legajo, 689).

${ }_{37}$ Así lo indica el Reglamento del comité melillense en su Artículo 39, que atribuye a la Junta Directiva funciones culturales como la organización de conferencias e incluso la fundación de escuelas. Resulta obvio que los viejos ideales del republicanismo histórico español pueden rastrearse $\sin$ excesiva dificultad en tales propósitos.

38 La misión que las actividades de carácter asistencial, cultural y lúdico organizadas por los partidos de masas desempeñan de cara a sus afiliados se relaciona, como ha sugerido PANECIBIANCO, con la necesidad de los dirigentes de proporcionar a aquéllos incentivos que aseguren su pertenencia en el partido y el incremento de su fidelidad hacia él. Algunos afiliados y votantes más creyentes tienen suficiente con los incentivos colectivos, basados en el sentido de pertenencia a una comunidad unida por un ideal común, pero otros, los arribistas, necesitan incentivos selectivos, de orden material, entre los cuales se cuentan “...servicios colaterales de asistencia, de organización del tiempo libre, de recreo..." (Panebianco, A.: Modelos..., pp. 70 y ss). 
progresismo. Actividades como las conferencias son mucho más frecuentes que, por ejemplo, los cursos, y, dentro de aquéllas, los temas escogidos, a pesar de su proclamado carácter interclasista, no podían dejar de interesar mucho más a las clases medias y acomodadas que a las obreras, como demuestra la hegemonía que los asuntos de índole jurídica tienen sobre todos los demás. ${ }^{39}$

El órgano inmediatamente superior al Comité municipal en la estructura organizativa progresista es el Comité Provincial. Como puede suponerse, su composición reproduce a mayor escala la de sus subordinados: Ios Comités locales elegían delegados que, reunidos en Asamblea provincial, votaban un Comité Provincial. La composición de éste era tan variada en cuanto al número de sus componentes como en el caso de los Comités locales, pero constante en la presencia de algunos cargos imprescindibles, como Presidente, Vicepresidente, Secretario y vocales. Asimismo, sus obligaciones no difieren mucho de las que asumian sus homónimos en las ciudades y pueblos, pues al obligado compromiso con la difusión de los ideales y el programa del partido se añade tan sólo una no menos evidente función de coordinación de las actividades de sus agrupaciones locales. En cuanto a los mecanismos utilizados en la elección de los cargos, los conocemos bastante bien por haberse conservado integro el reglamento del Comité Provincial de La Coruña ${ }^{40}$, el cual señala de forma explícita en su Artículo $5 .^{\circ}$ que "La organización provincial se forma con los delegados de los Comités Municipales los que reunidos constituyen la Asamblea general y eligen de su seno un consejo o Comité provincial compuesto de vocales", para aclarar después que dicha elección se producirá anualmente y será indiferenciada, esto es, corresponderá luego a los vocales elegidos decidir quiénes de entre ellos habrán de ocupar los cargos. Del mismo modo, el Artículo $13 .^{\circ}$ aclara que cada Comité municipal, sea cual sea el volumen de afiliación con que cuente, no podrá nombrar más que un delegado, y que éste contará tan sólo con un voto.

Para terminar este punto es necesario aludir a la existencia de lo que podria haber sido un incipiente proceso de creación de organismos regionales. La posibilidad de crear instituciones de este tipo, a medio ca-

39 Véase, sobre todo, El Liberal de Madrid, que da información muy detallada y frecuente sobre actos de este tipo. Uno de los líderes progresistas que más se destacó en estas lides fue Juan Castrillo, que llegó a especializarse en temas relacionados con la mujer, pero abordó también otros más puramente politicos, como el análisis del contenido de las distintas ideologias del momento.

40 AHNS, Político-Social, Madrid, carpeta 1897. 
mino entre la organización provincial y la nacional, ya estaba prevista cuando la entonces Derecha Liberal Republicana comenzaba a dar sus primeros pasos en el verano de 1930, como prueba la carta ya aludida remitida por Manuel García Rodrigo, a la sazón Secretario General del partido, al secretario de un Comité local recién creado que había escrito a Madrid solicitando instrucciones. En el apartado titulado "Organización general del partido» se habla de «...Comités Provinciales o Regionales, o de una y otra clase conjuntamente, según los casos...", y las alusiones vuelven a repetirse en los siguientes párrafos. Meses después, los Estatutos del PRP seguían dejando libertad a las agrupaciones provinciales de una misma región para «...federarse entre si para los fines concretos que ellas mismas determinen" (artículo 50). Lo cierto es, no obstante, que tales organismos regionales no se constituyeron en mucho tiempo y que cuando lo hicieron fueron la excepción y no la norma, pues sólo tenemos noticia de la existencia de uno de ellos, el de Galicia, explicable sin duda por el espíritu independiente y fuertemente regionalista que siempre tuvo el progresismo gallego, que, como veremos más adelante, acabaría por conducirle a la segregación para constituir un partido nuevo ${ }^{41}$. Los orígenes del Comité Regional Gallego del PRP, que estaba presidido por el delegado regional en el Consejo Nacional, Enrique Álvarez de Neyra, y constituido por cuatro miembros, uno en representación de cada provincia, se remontan a fecha tan tardía como octubre de 1933. En esa fecha se celebró un Congreso regional ${ }^{42}$ en el que, tras ratificar el ideario del partido aprobado por el Comité Nacional el diez de julio de 1932, se introdujeron en él matizaciones en defensa de la autonomia integral no puramente administrativa ${ }^{43}$ para Galicia, y se declaró constituido el citado Comité Regional. Los derroteros posteriores que siguió éste prueban que el partido nunca se planteó en serio dotarse de una organización a nivel regional: si los progresistas gallegos se hubieran sentido integrados en una fuerza política verdaderamente organizada de acuerdo con criterios de descentralización regional, no habrían tenido motivos para marcharse.

41 La escisión tuvo lugar en marzo de 1934 y dio lugar a la fundación del denominado Partido Republicano Progresista Autónomo Gallego, según indica la carta remitida por entonces al Comité Ejecutivo Nacional del PRP (AHNS, Politico-Social, Madrid, carpeta 1897).

42 Primer Congreso del Partido Republicano Progresista en Galicia. Acta. Lugo, 7 de octubre de 1933. AHNS, Politico-Social, Madrid, carpeta 1897.

43 El documento afirma que el partido «...propugna para Galicia una autonomia de tipo político, democrática y descentralizadora dentro de la Región, pero apoyará la autonomía que Galicia vote en el plebiscito". Sin duda, el PRP procedia en este asunto con completa independencia de sus órganos centrales en Madrid. 


\section{LA ORGANIZACIÓN NACIONAL}

La estructura del partido a este nivel se fundamenta sobre la existencia de tres organismos: uno de ellos de carácter representativo de la totalidad de los afiliados y de convocatoria periódica, la Asamblea Nacional; otro de gobierno y ejecución, el Comité Ejecutivo Nacional, que, ampliando con representantes regionales y altos cargos políticos, de forma el Consejo Nacional, de índole consultiva, y un tercero administrativo y burocrático, la Secretaría General.

La Asamblea Nacional es el órgano soberano, representativo y deliberante. En ella se aprueban el ideario, el programa y los Estatutos del partido, así como las reformas organizativas que puedan introducirse; como es natural, se elige por votación a los integrates del Comité o Junta Nacional y se aprueba o rechaza su gestión, y se trazan las líneas básicas de la táctica a seguir de cara a la articulación de alianzas más o menos estables con otras fuerzas a nivel nacional. Está compuesta por delegados de los Comités municipales elegidos directamente ${ }^{44}$, así como por representantes de las secciones autónomas, es decir, la Juventud y la Sección Femenina. Estos delegados han sido escogidos por votación en asambleas extraordinarias convocadas con tal fin por las diferentes agrupaciones y cada uno de ellos puede representar a más de una, exigiéndoles habitualmente una credencial que, una vez válida por la mesa provisional de la Asamblea, otorga a su portador el derecho a voz y voto en las sesiones que celebre. Los simples afiliados, por lo general, suelen tener acceso a la Asamblea y voz en ella, aunque para ello se les viene exigiendo haber obtenido algún tipo de identificación en la Secretaria General, pero no se les concede voto. Los miembros del partido que ejercen cargos públicos nacionales reciben también el derecho a contar con voz y voto aunque no ostenten la representación de ninguna agrupación.

La labor previa a la Asamblea solía incluir el envío a los Comités y demás agrupaciones del partido de la convocatoria de la misma, así del orden del día previsto. Entonces se procedía a la discusión de los temas propuestos y a la aprobación de una postura oficial que los delegados debían defender en la Asamblea, sin que estuviera prohibida la inclusión

44 Circular remitida por la Secretaria General del PRP a los Comités Municipales del partido con motivo de la celebración de la Tercera Asamblea Nacional, 15 de junio de 1933. AHNS, carpeta 1897. La circular aparece también reproducida en el órgano progresista madrileño, La Defensa, el 5 de julio del mismo año. El mecanismo de elección se refleja también en los artículos 27 al 31 de los Estatutos del partido. 
de temas no contemplados en el orden del día, aunque en este caso, una vez redactados en forma de ponencia, debian remitirse a Madrid antes del inicio de las sesiones para su incorporación, sin la cual no resultaría posible una organización racional de los trabajos previstos.

Las sesiones se prolongan por espacio de dos o tres días, que suelen coincidir con el fin de semana para facilitar los desplazamientos de los delegados de provincias, ya que todas las asambleas se celebran siempre en Madrid. Su periodicidad teórica es anual, pero el Partido Republicano Progresista sólo se aproxima al cumplimiento preciso de esa norma, limitándose a celebrar cuatro Asambleas Nacionales en el período que transcurre entre su fundación en el verano de 1930 y el estallido de la Guerra Civil seis años después.

La Asamblea da comienzo con la constitución de una mesa provisional -habitualmente el propio Comité Nacional o las personas que él designe- que preside las tareas de verificación de credenciales, aprobación del reglamento y elección de la mesa definitiva. La discusión de cada tema suele iniciarse con un discurso de presentación por parte del portavoz de la comisión que haya redactado la ponencia, casi siempre compuesta íntegramente por miembros del Comité Nacional, para lo cual cuenta éste con subcomisiones especializadas. Se produce a continuación las intervenciones, en número y extensión limitados por el reglamento, y la discusión concluye con la aprobación o el rechazo en votación plenaria de la potencia presentada. Terminados los trabajos previstos, un homenaje al presidente del partido y un discurso de éste a los postres de una comida celebrada en los salones de algún conocido restaurante madrileño ponía fin a las sesiones de la Asamblea.

Pero el órgano que ejerce la dirección efectiva del partido en los periodos que transcurren entre la celebración de las sucesivas Asambleas es el Comité Ejecutivo Nacional. Este organismo estaba integrado en sus comienzos por un reducido número de diputados y representantes provinciales, aunaba las funciones de deliberación y ejecución y se erigía en "Autoridad Suprema, que trazaba las normas generales de la actuación, con visión amplia de los problemas nacionales..." ${ }^{45}$. Pero tal organismo,

${ }^{45}$ Copia de una carta...,AHNS, Político-Social, Madrid, carpeta 625, legajo, 869. Dicho Comité quedó integrado provisionalmente por los personajes más destacados de entre los fundadores de la Derecha Liberal Republicana, para pasar tras su Primera Asamblea Nacional, en agosto de 1931, a la composición que se indica. En dicha Asamblea fueron elegidos para integrar el Comité, de forma indiferenciada, César Juarros, Federico Fernández Castillejo, Mariano Gómez, Enrique Álvarez de Neyra, Agustín Pérez Lizano, Rafael Sánchez Guerra y Niceto Alcalá Zamora y CastiIlo (Ahora, 6 de agosto de 1931). De ellos, los dos primeros eran diputados, mientras los demás 
incapaz de responder a las necesidades de los que se pretendía que fuera un partido moderno, hubo de ser reformado rápidamente. En la Segunda Asamblea Nacional (marzo de 1932) se desdoblaron sus funciones, separándose ejecución y deliberación. La primera quedó en manos del antiguo órgano, que fue ampliado hasta los diecisiete miembros y tómo el nombre de Comité Ejecutivo Nacional ${ }^{46}$. En su seno se crearon seis comisiones especializadas ${ }^{47}$, que revelan por sí solas las funciones que se arrogaba el Ejecutivo progresista en su nueva andadura (Disciplina y Régimen Interior, Hacienda, Ideario, Organización, Propaganda y Técnica) y muestran lo que parece un intento evidente de relanzar la vida de un partido que languidecía tras la secesión encabezada por Maura.

Las funciones consultivas y de deliberación pasaron entonces a manos de un Consejo Nacional, integrado por el Comité Ejecutivo Nacional más representante de cada uno de los Comités Provinciales, otra de la Sección Femenina, y la totalidad de los diputados del partido ${ }^{48}$, lo que elevaba el número de miembros del nuevo organismo a nada menos que veintiocho. Su misión principal, a la luz de lo que cabe deduccir de las escasas reuniones que celebraba, era la alta dirección política del partido, la fiscalización de sus acuerdo y alianzas con otras fuerzas y la supervisión y control de la labor del grupo parlamentario.

representaban a Valencia, Galicia, Zaragoza y Madrid, por este orden. La elección de cargos en el seno del comité se produjo después, en la primera reunión de éste, que no tuvo lugar hast el 31 de octubre, fecha que figura en la primer reunión de éste, que no tuvo lugar hasta el 31 de octubre. fecha que figura en la primera página del correspondiente libro de actas (AHNS, Político-Social, Madrid, carpeta 625, legajo, 689). La presidencia recaería en César Juarros, correspondiendo a Fernández Castillejo y Niceto Alcalá Zamora y Castillo los cargos de Secretario General y Tesorero, respectivamente.

46 AHNS, Político-Social, Madrid, carpeta 1897. César Juarros seguía siendo el Presidente; se creaban dos vicepresidencias, ocupadas respectivamente por Juan Castrillo y José Maria Roldán, y la Secretaría General pasaba a manos de Manuel Garcia Rodrigo, auxiliado por Rafael Fernández Carril como Vicesecretario y Rafael Navarro como Secretario de actas. El Comité se completaba con Juan Diego del Campo como Tesorero, Mariano Jiménez Díaz como Contador, y nueve vocales: Federico Fernández Castillejo, Vicente Sales Musoles, Alfredo Zabala, Julio de Ramón Laca, Heliodoro Suárez Inclán, José Sarthou, Vicente Armada, Eduardo Pardo Reina y Eugenio Ruiz Gálvez.

47 Reunión del Comité Ejecutivo Nacional, celebrada el día 4 de marzo de 1932. AHNS, Político-Social, Madrid, carpeta 627, legajo, 869.

48 AHNS, Político-Social, Madrid, carpeta 1897. Aunque la decisión sobre la creación del Consejo data de la Segunda Asamblea Nacional, no se constituyó hasta el 9 de julio de 1932. Su constitución queda clara en una noticia publicada por La Defensa el 14 de junio de 1933 en la que se indica que "Ayer tarde se reunió en sesión plenaria con asistencia de las representaciones provinciales, Comité Nacional y Minoría Parlamentaria, el Consejo Nacional del Partido Republicano Progresista, convocado con urgencia para fijar la actitud del partido y la conducta de la Minoria Parlamentaria frente a la actual situación política». La presencia de una representante de la Sección Femenina queda confirmada en un reportaje sobre la participación de la mujer en los distintos partidos republicanos que publicó Ahora el 9 de abril de 1933. 
No debió de funcionar muy bien, sin embargo la nueva organización de la cúpula progresista. El examen de las actas del Comité Ejecutivo Nacional revela el escaso interés que sus integrantes tuvieron desde el principio en asistir a sus reuniones ${ }^{49}$, impresión que cabe hacer extensiva al Consejo Nacional, y desde luego no fue muy grande el éxito obtenido de cara al perseguido incremento de militancia en el partido. Por ello, la Tercera Asamblea Nacional volvió a introducir reformas significativas: hace obligada la reunión cuando menos mensual del Consejo $\mathrm{Na}$ cional; limita a nueve los integrantes del Comité Ejecutivo Nacional; le proporciona el apoyo de un órgano asesor de carácter técnico, el denominado Secretariado Técnico, dividido en seis secciones: Organización, Propaganda y Prensa, Asuntos Sociales, Asuntos Políticos, Asuntos Administrativos y Asesoría Jurídica, y crea, por último, una Comisión Central de Propaganda, con la misión de coordinar las campañas del partido a nivel nacional, para lo que contará con un entramado de comisiones regionales y provinciales dependientes de ella. Se trata, en última instancia, de un nuevo esfuerzo para sacar al progresismo de la inoperancia, el enésimo, y su resultado no diferirá mucho de los anteriores ${ }^{50}$.

El tercero de los órganos centrales progresistas era la Secretaría General. Al contrario que los otros dos, se trataba de una entidad de índole burocrática encargada de la gestión administrativa. Es ella la que se ocupa, en los primeros momentos de la vida del progresismo, de dirigir y organizar el proceso de constitución de los comités locales, inscribiendo a los nuevos afiliados en el censo del partido, remitiendo instrucciones, carnets, reglamentos e impresos de propaganda. Será también de su competencia la preparación de las Asambleas a instancias de Comités Nacional, remitiendo circulares y ponencias, recibiendo certificaciones de los Comitén que aspiran a representación y otorgando validez a ésta, funciones todas ellas que permanecerán inalterables con el paso del tiempo.

\section{LAS SECCIONES AUTÓNOMAS}

Al igual que la mayoría de las fuerzas políticas de su tiempo, la DLRPRP contaba con organismos destinados a la captación, encuadramiento y

49 El acta del 8 de marzo de 1932 dice literalmente que «...se habla de la necesidad de estimular a los miembros del Comité Nacional, para que no falten a las reuniones del mismo, ni de las comisiones de que forman parte..." (AHNS, Político-Social, Madrid, carpeta 627, legajo 869).

50 El documento de Conclusiones de la Asamblea, fechado el 16 de julio de 1933, dedica todo un capitulo, bajo el epigrafe "Normas de organización», a estas cuestiones. 
movilización de ciertos sectores sociales concretos dotados de una personallidad especifica y un volumen suficiente para hacer su atracción rentable en términos políticos. Estos sectores son, sobre todo, la juventud, cuyo valor estriba en la conveniencia de moldear desde los primeros momentos las dúctiles mentes juveniles para formar asi una cantera de futuros militantes entusiastas y preparados, y la mujer, determinante desde el punto de vista cualitativo en su papel de primera educadora y desde el punto de vista cuantitativo, una vez que se le concede el voto, por suponer cerca de la mitad del censo electoral.

La organización y evolución de la Sección Femenina va a caracterizarse por los siguientes rasgos fundamentales:

1. Tardio y escaso interés por la mujer como sujeto político. La fundación de la Sección Femenina no fue paralela a la del partido, sino posterior, hecho que quizá cabría vincular al retraso con el que el que el nuevo régimen concedió a la mujer el derecho al sufragio, ya que, como es sabido, en las primeras elecciones generales, las de junio de 1931, el censo estaba aún compuesto sólo por hombres. Es posible pensar, por tanto, que entre los progresistas no existía un verdadero convencimiento acerca de la igualdad política de la mujer, ni un interés profundo en su movilización, pues, de haber sido así, no se habría esperado a dar vida a la Sección Femenina del partido al momento en que hacerlo comenzaba a ser rentable en términos electorales. Lo cierto es que los progresistas no manifiestan interés alguno hasta casi mediar $1932{ }^{51}$. El encuadramiento político de la mujer, además, se inicia como resultado de la iniciativa individual de algunas pocas personas que dedican sus energías a ello, como el doctor César Juarros, que llega a desarrollar una actividad incansable en pro de los derechos de la mujer, organizando e impartiendo conferencias o interviniendo en las Cortes ${ }^{52}$.

51 El Sol informa el 8 de mayo de 1932 de la inminente celebración de "...la primera reunión feminista de las varias que prepara el partido". Parece que es la primera referencia de una cierta actividad de la Sección Feminista progresista, pues aunque quizá existía un "Comité Central Femenino" de cuya reelección nos habla el mismo diario el día 25 , no debía de llevar mucho tiempo en activo, ya que un acta del Comité Ejecutivo Nacional progresista del 31 de marzo de 1932 da constancia de la Sección Femenina en esa fecha.

52 César Juarros habló en defensa del voto femenino cuando se discutía este asunto dentro de los debates constitucionales (Diario de Secciones de las Cortes Constituyentes -en adelante DSCC-, 30 de septiembre de 1931). Resulta interesante sobre este aspecto la consulta del trabajo de Mary NASH: "Género y ciudadanía", en Ayer, n. ${ }^{\circ} 20,1995$, pp. 241-258. Asimismo, puede seguirse la evolución del problema de la concesión del voto a la mujer y las diferentes posturas al respecto en CALPE, Rosa M. :El sufragio femenino en la Segunda República española. Madrid, 1992. No menos interesantes resultan los testimonios de una de las principales protagonistas del debate en los años treinta, la diputada radical Clara Campoamor: Mi pecado mortal. El voto femenino y yo. Barcelona, 1981. 
Los frutos de tal actividad, no obstante, parecen escasos: el partido no llegará a contar en su mejor momento más que con unas decenas de afiliadas ${ }^{53}$.

2. Una organización paralela a la del partido y dependiente de sus instancias masculinas. La autonomía de la que la Sección Femenina del progresismo hace gala es, además, más aparente que el real. Es cierto que, a grandes rasgos, se nos presenta como una estructura paralela a la del partido-madre que copia sus agrupaciones en los niveles locales y la culmina en Madrid con un organismo central que está representado en el Consejo Nacional del partido por una o dos delegadas escogidas con tal fin. Pero un examen más detallado revela cómo las mujeres que ocupan los cargos de responsabilidad son esposas o hermanas de los jefes masculinos del partido, lo que sugiere que aunque se produjera de hecho un proceso electoral libre en el seno de la Sección Femenina, éste estaría condicionado por el control previo de las candidatas por los hombres. Sin su beneplácito previo, al menos, seria imposible que se moviera nada.

3. Un concepto de la mujer que continúa basándose en la aceptación de la existencia de una naturaleza femenina distinta de la masculina que hace a aquélla acreedora de un status social y unos roles distintos a los del hombre. Aunque no figura el progresismo entre los partidos que se valen del sexo femenino en beneficio de una opción retardataria que, de triunfar, haría de él uno de los principales colectivos perjudicados, tampoco pueden interpretarse en un sentido feminista las afirmaciones de sus dirigentes en favor de una integración total de la mujer en la política activa. Sus líderes, y en especial César Juarros, defienden su emancipación, entendiéndola en un sentido amplio que pasa por el reconocimiento de su igualdad en derechos con el hombre en lo laboral, lo social y lo político, así como en lo relativo al matrimonio y la potestad sobre los hijos, el acceso a la enseñanza en todos sus grandos y a la administración pública sin discriminación alguna. Pero la contradicción surge a poco que se lean con detenimiento unos pocos discursos y artículos, de los que difícilmente puede extraerse una conclusión distinta de la evidencia de que los progresistas siguen creyendo en la posesión por parte de la mujer de una psicología y unas virtudes especiales que derivan de su condición natural de madre y la cualifican prioritariamente para el desempeño de una serie

\footnotetext{
53 De entre los varios miles de fichas de afiliación al PRP que se han conservado, sólo unas cuarenta corresponden a mujeres. AHNS, Político-Social, Madrid, carpeta 534, legajos 4808 y 4809 ; carpeta 627 , legajo 689 , y carpeta 628 , legajo 872 .
} 
de funciones sociales y políticas, lo que supone de forma implicita excluirla de otras que seguirán siendo coto cerrado del hombre porque exigen capacidades que la mujer no posee, como la racionalidad, la competividad o la firmeza. No se piensa ni por asomo en la plena igualdad. Se asume que la mujer es distinta, que posee virtudes diferentes y que, en consecuencia, sus cometidos en la sociedad han de ser también diferentes, no tan limitados como los tradicionales, pero distintos ${ }^{54}$. Las posibilidades de acción política que tales perjuicios dejaban a la Sección femenina del PRP no podían dejar de ser más bien limitadas.

$Y$ así era en efecto. De la idea de que todas las mujeres no son sino madres en potencia, que deben integrarse en la sociedad mediante labores asistenciales, surgió todo el catálogo de actividades a las que se entregaban las mujeres progresistas. Damas la mayoría de ellas acomodadas o de clase media; solteras, casadas o viudas; jóvenes o maduras, pero con tiempo libre y recursos suficientes para ello, dedicaban sus esfuerzos a la organización de cursillos, la recogida de juguetes para los niños pobres, o la celebración de veladas literarias y conferencias en las que los oradores eran casi siempre hombres -el doctor Juarros destacó en esta labor - y los temas escogidos poco podían aportar para la verdadera emancipación de la mujer ${ }^{55}$. Sólo los períodos electorales, en los que cualquier persona era útil para colaborar en las actividades de propaganda, acercaban algo a las afiliadas al protagonismo que sus compañeros solían tener en la vida política del partido.

La historia de la Juventud del PRP no difiere en exceso de la que hemos trazado para la Sección Femenina. El interés que despierta en su seno la posible atracción de afiliados jóvenes es también escaso y tardío. En fecha tan avanzada como el verano de 1932 aún no se había constituido oficialmente la Juventud, o eso parece lógico deducir de una carta remitida el 27 de julio de dicho año al Presidente del Comité de Chamberí en la que el abogado madrileño Vicente A. Gómez se ofrece para «...ver si habría posibilidad de organizar la Juventud del partido" ${ }^{56}$. Además, una

\footnotetext{
54 Y no eran sólo los hombres sino las mismas mujeres las que parecian pensar asi. Un artículo aparecido en el órgano progresista La Defensa el 27 de mayo de 1933 bajo el título «El deber de la mujer" firmado por Lucrecia, sostenia que la mujer debía participar plenamente en la vida política, pero, aso sí, para “...suavizar la aspereza de las luchas de los hombres...".

55 Juarros hacia mucho hincapié como profesional que era de la medicina en las diferencias fisiológicas y psicológicas entre los dos sexos, aunque también dedicó un ciclo de charlas a la visión de la mujer en las distintas ideologías políticas. No tenemos noticias, sin embargo, de alusión alguna a temas como la sexualidad o la planificación familiar, que tanto preocupaban, por ejemplo, a las publicaciones anarquistas de la época.

56 AHNS, Político-Social, Madrid, carpeta 630, legajo 873.
} 
vez organizada, ésta apostó por una estructura similar a la de la Sección Femenina, esto es, autónoma en su funcionamiento interno, pero paralela al partido-madre y dependiente de sus Comités a todos los niveles. Los jóvenes afiliados al progresismo, cuyas actividades y relaciones con sus mayores conocemos con mucho detalle gracias al hecho de haberse conservado importante documentación al respecto ${ }^{57}$, contaban, lo mismo que las mujeres del partido, con muy poca autonomía real, pues necesitaban autorización del Comité del que dependian hasta para las actividades más irrelevantes. Desde luego, la elección de sus órganos de gobierno y la redacción de sus reglamentos no eran válidos en tanto no alcanzaran la aprobación de dicho Comité ${ }^{58}$, y sabemos que, en un caso al menos, el desacuerdo entre la dirección de la Juventud y el Comité del que dependía en cuanto a la orientación política de la primera motivó su disolución ${ }^{59}$. Incluso actos no demasiado trascendentales, como la participación en la celebración conjunta con que la proclamación de la Primera República, el 11 de febrero, parecian requerir la autorización del Comité correspondiente ${ }^{60}$.

En cuanto a las actividades en que las juventudes ocupaban su tiempo, es evidente que concedian el predominio a lo cultural y lo recreativo sobre lo político. Su organización corría a cargo de una serie de comisiones específicas que se creaban por nombramiento de la Junta de Gobierno y actuaban en conexión con ésta mediante la figura de un delegado para cada una de ellas. Aunque tales comisiones no fueron siempre las mismas, parece que las áreas de que se ocupaban eran la política, la cultura, el deporte, el arte y lo puramente recreativo. De hecho, las actividades concretas que sabemos llegaron a organizar, algunas de ellas sometidas a un reglamento ad hoc sorprendentemente detallado, iban desde las conferencias políticas de los líderes del partido a los bailes de salón, pasando por la organización de cursillos de capacitación profesional (taquigrafía, por ejemplo) o simple cultura general, y desde luego la

57 Contamos con el Reglamento de la Juventud progresista del Distrito madrileño de Chamberi-Hospicio (AHNS, Político-Social, Madrid, carpeta 627, legajo 870 ) y con un buen número de actas de las reuniones de su Junta Directiva (ibid., carpeta 630, legajo 873).

s8 Un acta de la votación que se celebró el 9 de noviembre de 1933 en la citada Agrupación de la Juventud progresista de Chamberi-Hospicio para la elección de su Junta Directiva afirma elocuentemente «...el carácter condicional de la proclamación, que deberá ser ratificada por la Junta Directiva del Partido" (AHNS, Politico-Social, Madrid, carpeta 630, legajo 873).

59 Sucedió, una vez más, en el Distrito madrileño de Chamberí-Hospicio, según recoge una Memoria de Secretaria de dicho Comité fechada el 14 de julio de 1933 (AHNS, Político-Social, Madrid, carpeta 627, legajo 870).

60 Asi se deduce de una carta remitida el 5 de febrero de 1935 al Comité Nacional por el Presidente de la Juventud Republicana Progresista madrileña en la que se solicitaba autorización para dicha participación (AHNS, Politico-Social, Madrid, carpeta 630, legajo 873). 
celebración de torneos deportivos y de campeonatos de parchís o damas, siempre limitados a los afiliados a la Juventud y a sus amigos y parientes directos, bajo la responsabilidad de los primeros.

Por desgracia, todas esas actividades a menudo quedaban sobre el papel, porque cuando se organizaban no siempre alcanzaban el éxito esperado, y a menudo no llegaban siquiera a celebrarse por falta de fondos para financiarlas. $Y$ es que el grado de incumplimiento de sus obligaciones en que incurrían los jóvenes afiliados progresistas era tal que no sólo las cuotas dejaban de abonarse de forma sistemática, sino que incluso el Secretario podía negarse a levantar acta de las reuniones y muchos directivos ni siquiera acudían a ellas. Quizá sea excesivo suponer que tales informaciones, referidas al Comité madrileño de Chamberí-Hospicio, son aplicables al conjunto de la Juventud del partido, pero tampoco hay razones para suponer que dicha agrupación fuera una excepción dentro de la misma. De ser no ser así, el grado de desorganización interna del partido a este nivel sería incluso superior al de su estructura adulta.

\section{LA BASE HUMANA DE PROGRESISMO Y SU IMPLANTACIÓN SOCIAL Y GEOGRÁFICA}

Descrita en sus aspectos más relevantes la estructura organizativa formal del Partido Republicano Progresista, de la que se ofrece una visión de conjunto en el Cuadro $n .{ }^{\circ} 1$, es el momento de afrontar lo que podía denominarse su valoración. En otras palabras, se trataría de comprobar cuál era la distancia entre lo que establecian sus Estatutos y proclamaban a los cuatro vientos sus líderes, y lo que la realidad, de forma contumaz en ocasiones, se obstinaba en demostrar. Comenzaremos para ello por analizar la base humana del partido, esto es, el volumen, la extracción socioeconómica y profesional de sus afiliados y dirigentes y su distribución por la geografía española. Después nos ocuparemos de dilucidar hasta qué punto tenían aplicación en la práctica sus postulados de democracia, participación y autonomía interna, para determinar así, como conclusión última de este trabajo, en qué punto de madurez organizativa, en la línea que va de los partidos de cuadros a los de masas, cabe ubicar al partido fundado por Niceto Alcalá-Zamora y sus seguidores más íntimos bajo la denominación de Derecha Liberal Republicana.

Afortunadamente, contamos para ello, como ya dijimos, con una información bastante rica, que se concreta en varios miles de boletines y fichas 
La Derecha Liberal Republicana: un modelo de organización de un partido...

\section{Cuadro n. ${ }^{\circ} 1$}

\section{Estructura organizativa de la DLR-PRP}

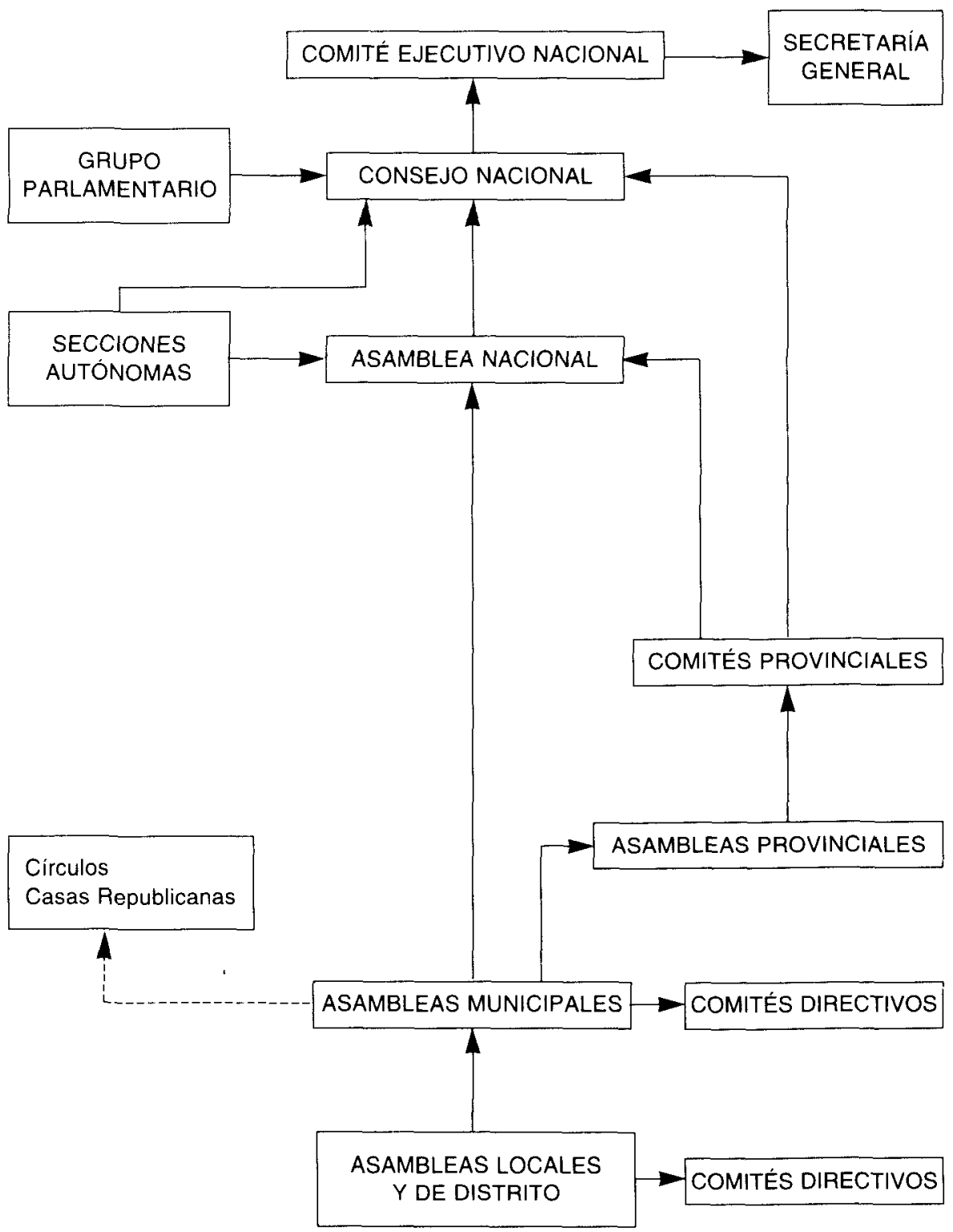

(Elaboración propia sobre documentación interna y prensa periódica). 
de afiliación ${ }^{61}$, y que proporciona, si no un universo muestral lo bastante representativo estadisticamente como para extraer conclusiones definitivas, sí un muestreo al azar lo bastante completo para definir una tendencia que sólo podrá ser comprobada si en un futuro se encuentra nueva documentación más completa que la disponible hasta la fecha. Así deben, pues, entenderse las conclusiones que presentamos a continuación.

En primer lugar, podemos analizar la estructura de la afiliación al progresismo en función de las cuotas con que los aspirantes a militar en las filas del partido se inscribían en el momento de solicitar su ingreso (Cuadro $n .{ }^{\circ} 2$ ). El interés de estos datos es doble. Por una parte, nos dicen ya algo de la extracción social mayoritaria entre las bases del partido, cuyo estudio completaremos después con los datos sobre profesionales, $y$, por otra parte, y sobre todo, proporcionan valiosa información sobre su financiación.

Como habrá podido observarse, al menos uno de cada diez afiliados $(11,35 \%)$ se inscribe con una cuota nula o inferior a una peseta, a pesar de que dicha posibilidad estaba expresamente prohibida en los mismos boletines de afiliación, en los que se indicaba con total claridad que la contribución personal a los fondos del partido podía oscilar entre una y diez pesetas mensuales. Aunque había contado en un principio con fuentes extraordinarias de financiación gracias al desahogado nivel de vida de Alcalá-Zamora y sus amigos políticos ${ }^{62}$, este incumplimiento sis-

61 Estamos hablando de un conjunto de legajos hallados en el Archivo de Salamanca que contienen documentación interna del progresismo, más concretamente, de los siguientes, todos ellos pertenecientes a la Sección Política-Social, Madrid: la carpeta 534, legajos 4808 4809, que contiene más de setecientas fichas de afiliación a la DLR con nombre y apellidos del afiliado, su residencia, profesión, cuota con la que se inscribe y, a veces, actividades políticas previas; la carpeta 625, legajo 689, que contiene una relación de los afiliados al partido en la ciudad de Zaragoza, con nombre, apellidos y profesión; la carpeta 628 , legajo 872 , que contienen dos millares de boletines de inscripción que los aspirante a afiliados cumplimentaban en el momento de solicitar la adhesión y recogen, además del nombre, la fecha, profesión, cuota y actividades políticas previas; la carpetaa 639 , legajo 873 , que contiene la lista de asociados al Subcomité madrileño de Hospital, aunque de ellos indica sólo la profesión. Asimismo, la carpeta 1917 nos ha proporcionado la relación de socios fundadores de la DLR, es decir, aquellos, que aportaron una cuota inicial de cien pesetas, y la carpeta 627 , legajo 871 , la lista de afiliados del partido que satisfacian cuotas extraordinarias y una relación de los afiliados al Comité de Priego de Cuenca, incluyendo nombre y profesión. La misma carpeta, en el legajo 870 , aporta idéntica información sobre el Comité provincial de Almería. Por último, en la carpeta 1897 hemos hallado la relación de afiliados de Monterrubio (Badajoz) con sus profesiones. Naturalmente, las conclusiones estadisticas que aparecen en este apartado han sido extraidas después de una concienzuda labor de comparación para eliminar posibles duplicaciones de datos.

62 La fundación del partido fue posible porque un grupo de amigos de Alcalá Zamora asumió los gastos iniciales mediante vales de 150 pesetas y suscribió tambièn cuotas especiales de fundador de cien (documento fundacional de la DLR, sin fecha ni título, AHNS, Político-Social, Madrid, carpeta 630, legajo 873). A estos se sumaron después, pero también en las primeras se 
La Derecha Liberal Republicana: un modelo de organización de un partido...

Cuadro n. ${ }^{\circ} 2$

Cuotas de los afiliados al partido republicano progresista

\begin{tabular}{crrcrrrrrr}
\hline $\begin{array}{c}\text { Cantidad } \\
\text { (pts./mes) }\end{array}$ & N. ${ }^{\circ}$ abs. $\%$ & $\begin{array}{c}\text { Cantidad } \\
\text { (pts/mes) }\end{array}$ & N. ${ }^{\circ}$ abs. $\%$ & $\begin{array}{c}\text { Cantidad } \\
\text { (pts./mes) }\end{array}$ & N. ${ }^{\circ}$ abs. & $\%$ \\
\hline 0 & 227 & 11,11 & 4 & 4 & 0,20 & 10 & 49 & 2,40 \\
0,5 & 5 & 0,24 & 5 & 195 & 9,54 & 25 & 2 & 0,10 \\
1 & 1.000 & 48,90 & 6 & 1 & 0,05 & 50 & 4 & 0,20 \\
1,5 & 14 & 0,66 & 7 & 0 & 0,00 & 75 & 2 & 0,10 \\
2 & 426 & 20,84 & 7,5 & 1 & 0,05 & 100 & 6 & 0,29 \\
2,5 & 10 & 0,49 & 8 & 1 & 0,05 & 150 & 1 & 0,05 \\
3 & 96 & 4,70 & 9 & 0 & 0,00 & TOTAL & 2.044 & 100 \\
\hline
\end{tabular}

(Elaboración propia sobre datos recogidos en la nota $n .^{\circ} 61$ )

temático obligó al progresismo, entonces aún Derecha Liberal, a hacer de la necesidad virtud y, disfrazando de conciencia social lo que no era sino una imposición de las circunstancias, suprimir el carácter obligatorio de la cuota. Así lo recoge, al menos, una carta remitida al prohombre alicantino Juan Bautista Catalá Gavilá el 9 de septiembre de 1931 por la Secretaria General de PRP en Madrid en la que se recueda que sólo será obligatoria la cuota al Comité local ${ }^{63}$. Pero ni siquiera una rendición tan rápida e incondicional por parte de los organismos centrales del partido sirvió de mucho. Por un lado, los afiliados que se comprometian a satisfacer cuota a la Secretaria General lo hacian con una cantidad tan baja que difícilmente bastaba para proporcionar una cantidad suficiente para hacer frente a unos gastos mínimos, ya que, como se ve en la tabla, más del sesenta por ciento de los afiliados se comprometian a pagar una peseta al mes o menos. Por otro lado, ni esas cuotas tan infimas, ni -éstas sí obligatorias- las que debian abonarse a los Comités locales se pagaban con una mínima regularidad. Aunque no sabemos con total seguridad cuál era el grado exacto de incumplimiento de

manas, otras personas que, en número de cuarenta, suscribieron cuotas semejantes de cien pesetas (Lista de fecha 9 de septiembre de 1930, AHNS, Politico-Social, Madrid, carpeta 1917). Este sistema de cuotas extraordinarias no desapareció nunca por completo, pues los miembros del Comité Nacional satisfacian cantidades mensuales de entre 25 y 150 pesetas, que también asumían voluntariamente otros militantes (Documento sin fecha, AHNS, Político-Social, Madrid, carpeta 627, legajo 871 ).

63 AHNS, carpeta 1897. La carta indica que "...no es indispensable para los afiliados consignar cuota conque [sic] hayan de contribuir a los gastos generales del partido, pues se tomó el acuerdo en vista de que muchos de ellos, y más en las localidades pequeñas, son pobres, que lo obligatorio sea tan sólo la cuota del Comité Local, sin perjuicio de que los afiliados que puedan contribuyan independientemente del Comité a los gastos de la agrupación". 
las obligaciones económicas de los afiliados, sí podemos afirmar que debía de ser muy alto, tanto más cuanto, a pesar de que los reglamentos solían imponer la expulsión a quienes se retrasaran dos meses en el abono de sus cuotas, tal sanción, que sepamos, llegaron a no estar al corriente de pago alrededor de un tercio, y es bien posible que dicho nivel de absentismo en el pago de las cuotas llegara a superarse en algún momento ${ }^{64}$.

La situación financiera en que esta indisciplina de la afiliación colocaba al progresismo era poco menos que extrema, de modo que si sobrevivía era tan sólo gracias a la existencia de mecanismos extraoficiales de financiación, como las aportaciones extraordinarias de los líderes. Éstas no fueron tan sólo un recurso inicial para echar a andar la maquinaria del partido, ni un suplemento más o menos importante de sus ingresos, como podría pensarse, sino el capítulo fundamental de las finanzas de PRP. Un Detalle de los ingresos y gastos habidos en el partido desde su creación hasta la fecha, fechado en Madrid el 12 de octubre de $1931{ }^{65}$, revela cómo la organización progresista habia ingresado un total de $17.593,70$ pesetas entre mediados de agosto de 1931 y la fecha citada. De esta cantidad, nada menos que 14.834 pesetas (el $84,31 \%$ ) habían sido aportadas por Niceto Alcalá Zamora y Castillo, cuya ascendencia familiar no es necesario comentar. En otras palabras, el partido, como bien concluye Juan Avilés ${ }^{66}$, estaba siendo financiado casi por completo por su fundador, el futuro Presidente de la República. Las consecuencias que este hecho puede sobre el funcionamiento interno del partido, por muy democrático que se proclame, son evidentes.

Así pues, lo que los documentos fundamentales y los reglamentos dibujaban como una fuerza política moderna, financiada mediante un sistema de cuotas de sus afiliados ${ }^{67}$, como era propio de los partidos que eran

\footnotetext{
64 Asi lo refleja un documento sin fecha que contiene una relación de los afiliados a dicho Distrito con indicación del estado de sus cuentas con el partido (AHNS, Político-Social, Madrio, carpeta 630 , legajo 873 ). De 108 individuos que figuran en la relación, 32 tienen al menos una cuota pendiente de abono.

65 AHNS, Político-Social, Madrid, carpeta 627, legajo 871

66 AVILÉS FARRÉ, Juan: "La derecha republicana: 1930-1936». Revista de Estudios Sociales, n. 16 , enero-abril de 1976 , pp.77-117, p. 90.

${ }_{67}$ La carta ya citada que el entonces Secretario General Manuel García Rodrigo remitió el 26 de agosto de 1930 al Secretario de un Comité local que le habia pedido instrucciones decía ya, no obstante, que el significado de la cuota sería en la Derecha Liberal Republicana distinto al que tenía en los partidos obreros, pues “...la indole de nuestro partido, la posición y cultura de sus componentes, las circunstancias en las que quiere vivir y desenvolverse, son factores que permiten esperar pueden acomodarse a este país costumbres ya en uso en todos los paises civilizados". (AHNS, Político-Social, Madrid, carpeta 625, legajo 869).
} 
- aspiraban a ser de masas, se nos aparece en la realidad como algo mucho más próximo, al menos en cuanto a su financiación, a un partido burgués de cuadros tradicional, sostenido por la fortuna de sus dirigentes, que no sólo no reciben retribución alguna, sino que costean sus propias campañas electorales cuando se presentan a algún cargo público y sostienen con sus graciosas donaciones el mínimo aparato del partido. Sería, por tanto, correcto aplicar a la DLR la descripción que hace Maurice Duverger acerca de algunos partidos de cuadros que, abriéndose a los miembros ordinarios, imitan a los partidos de masas: "...su forma aparente corre el riesgo de engañar al observador. No hay que limitarse a las reglas oficiales planteadas en los estatutos, ni a las declaraciones de los dirigentes. La ausencia de un sistema de registro de los miembros o de una percepción regular de las cuotas es un criterio bastante bueno: no se concibe sin ellos, como se verá, una adhesión verdadera" ${ }^{68}$.

Cuadro $\mathrm{n}^{\circ} 3$

Extracción socioprofesional de los afiliados al PRP

\begin{tabular}{|c|c|c|}
\hline Profesión & N. ${ }^{\circ}$ absoluto & Porcentaje \\
\hline Médicos & 67 & 2,42 \\
\hline Farmacéuticos & 18 & 0,65 \\
\hline Practicantes & 12 & 0,43 \\
\hline Odontólogos & 8 & 0,29 \\
\hline Veterinarios & 5 & 0,18 \\
\hline Abogados & 158 & 5,71 \\
\hline Notarios & 5 & 0,18 \\
\hline Procuradores & 11 & 0,40 \\
\hline Secretarios Judiciales & 6 & 0,22 \\
\hline Profesores de Universidad & 13 & 0,47 \\
\hline Profesores de EEMM. & 18 & 0,65 \\
\hline Maestros & 23 & 0,83 \\
\hline Arquitectos & 1 & 0,44 \\
\hline Ingenieros & 24 & 0,87 \\
\hline Aparejadores & 10 & 0,36 \\
\hline Escritores y Periodistas & 33 & 1,19 \\
\hline Técnicos de grado medio & 28 & 1,01 \\
\hline Altos funcionarios & 14 & 0.51 \\
\hline Total profesionales universitarios & 595 & 21,52 \\
\hline
\end{tabular}

68 Duverger, Maurice: Los partidos..., p. 94. Subrayados nuestros. 
Cuadro $\mathrm{n}^{\circ} 3$ (continuación)

Extracción socioprofesional de los afiliados al PRP

\begin{tabular}{lcc}
\hline \multicolumn{1}{c}{ Profesión } & N. ${ }^{\circ}$ absoluto & Porcentaje \\
\hline Comerciantes e Indust. & 300 & 10,85 \\
Propietarios & 204 & 7,38 \\
Labradores & 232 & 8,39 \\
Tratantes, Agtes. Comerciales y Comisionistas & 80 & 2,89 \\
Armadores & 1 & 0,04 \\
Militares profesionales & 35 & 1,27 \\
\hline Total clases medias no universitarias & 851 & 30,78 \\
\hline Empleados & 240 & 8,68 \\
Correos y Telégrafos & 33 & 1,19 \\
Dependientes de Comercio & 93 & 3,36 \\
Artistas y Músicos & 8 & 0,29 \\
Clero (sacerdotes y ministros no católicos) & 6 & 0,22 \\
Patrones de barco, pilotos y marineros & 16 & 0,58 \\
Bajos funcionarios de la Admón. Local y Cent. & 51 & 1,84 \\
\hline Total clases medias bajas & 447 & 16,17 \\
\hline Artesanos y Obreros urbanos cualificados & 263 & 9,51 \\
Obreros urbanos no cualificados & 212 & 7,67 \\
Proletariado rural & 331 & 11,97 \\
\hline Total proletariado & 806 & 29,15 \\
\hline Estudiantes & 66 & 2,39 \\
\hline Total afiliados estudiados ${ }^{69}$ & 2.765 & 100,01 \\
\hline
\end{tabular}

(Elaboración propia, sobre datos del AHNS)

69 Es necesario hacer algunas aclaraciones acerca de los criterios elegidos para ubicar profesionalmente a los afiliados. En primer lugar, cuando las profesiones con que el afiliado se inscribe son más de una (por ejemplo, abogado y periodista o abogado y propietario), lo cual es relativamente frecuente, hemos escogido siempre la primera por considerar que si se cita en primer lugar, es porque existe una mayor identificación psicológica con dicha ocupación. En segundo lugar, hemos modificado en ocasiones la expresión literal de la profesión que aparece en las fichas, por considerar que en el contexto en el que vive y trabaja el afiliado lo que quiere decir es diferente del significado que se asocia habitualmente al significante que el afilliado emplea. Así, un jornalero que vive en el centro de Madrid debe ser considerado obrero no cualificado y no bracero del campo, que es lo que sería de vivir en un medio rural. En ocasiones, por último, la ambigüedad en la que incurren las fichas nos obliga a tomar decisiones arriesgadas. Así, cuando nos encontramos con un panadero, ¿tenemos ante nosotros a un propietario de panaderia -esto es, a un industrial, como se decía entonces - o a un oficial panadero empleado de la misma? En estos casos, hemos optado, salvo evidencia en sentido contrario, por considerar afiliado como empleado. Lo mismo hemos hecho con la expresión, tan usual, del comercio, que interpretamos siempre como equivalente a dependiente de comercio. 
Al menos desde el punto de vista de la financiación, por tanto, el progresismo no puede ser considerado en modo alguno un partido de masas moderno. Veamos si lo es en algún otro aspecto, por ejemplo el de las características y extensión de sus bases sociales, para lo que tomaremos como punto de partida los datos recogidos en el Cuadro número 3 . De su observación podemos extraer algunas conclusiones relativas a las bases sociales del progresismo:

1. El predominio aplastante de las clases medias, que totalizan un porcentaje superior al $50 \%$ de los afiliados al partido, y ello a pesar de la distorsión que supone el hecho de que un buen número de las fichas consenvadas corresponden a dos o tres pueblos en que, sin duda por presión de sus patronos, una gran masa de jornaleros se sumó a las filas del progresismo.

2. La importancia fundamental de tres grupos dentro de las clases medias: los profesionales de formación universitaria $(21,52 \%)$, y dentro de ellos los abogados y los médicos, que juntos suponen en torno al $10 \%$ del total de afiliados; los comerciantes e industriales, es decir las gentes que viven de un negocio, por lo general pequeño o mediano en un medio urbano o semiurbano ${ }^{70}(10,85 \%)$, y los propietarios, grupo que plantea importantes problemas de valoración, pues sin duda su exiguo $7,38 \%$ habría de ser engrosado con una buena parte de los que se califican a sí mismos como labradores $(8,39)$, pues muchos de estos no son sino propietarios de fincas rústicas.

3. Las clases medias bajas urbanas, a menudo denominadas proletariado de cuello blanco por su condición económica precaria, que formaban tradicionalmente el grueso de la militancia del republicanismo, conservan, como puede verse, un peso considerable, superior al $15 \%$ de la afiliación. Si sumamos a este porcentaje el que aportan los obreros cualificados de las ciudades, no muy diferentes de ellos en cuanto a nivel de vida, alcanzaríamos una cifra superior al $25 \%$. En otras palabras, al menos uno de cuatro afiliados al PRP proviene de estos sectores.

4. El peso del proletariado urbano y rural es relativamente alto (se aproxima al $20 \%$ ) pero tal volumen no debe llamarnos a engaño, pues es fruto de la distorsión que comentábamos más arriba. Si de algo hay que considerar representativa la presencia de un grupo significativo de afiliados provenientes de los medios obreros campesinos es de lo contrario de lo que a simple vista parece. No se trata de que este sector apoyara sig-

\footnotetext{
70 En la España de los años treinta se denominaba industrial al propietario de un establecimiento en el que se elaboraba y se comercializaba un producto, hecho que tiende a hacer difusos los limites entre fabricantes y comerciantes tal como los entendemos hoy en día.
} 
nificativamente al progresismo, sino de que la pervivencia de mecanismo caciquiles en algunas zonas benefició al PRP, pues quienes detentaban el poder económico en el campo lo usaron para forzar a los jornaleros que de ellos dependían a incorporarse a una opción política con la que difícilmente podían sentirse identificados.

En suma, parece que nos encontramos ante un partido republicano que no se aparta mucho de la pauta de afiliación que venía siendo tradicional en la trayectoria del republicanismo histórico, nutrido sobre todo de elementos provenientes de las clases medias urbanas, profesionales liberales y pequeños propietarios, comerciantes e industriales principalmente. ¿Se ajustan a esta descripción también los dirigentes? Hay que señalar algunas diferencias. La extracción socioprofesional de los dirigentes locales, para comenzar, nos es bastante bien conocida gracias al hecho de haberse conservado en el Archivo de Salamanca varios centenares de actas de constitución de comités locales del PRP en las que se indica la profesión de los componentes de sus juntas directivas ${ }^{71}$. Los Comités locales, para empezar, estaban controlados sin duda alguna por los estratos superiores de las clases medias de acuerdo con un esquema según el cual, a mayor importancia del cargo, mayor peso de los profesionales de formación universitaria. Así, la inmensa mayoría de los presidentes (el $53,33 \%)$ han pasado por la Universidad, con claro predominio de médi$\cos (22,26 \%)$ y abogados $(16 \%)$, aunque los propietarios, comerciantes e industriales suponen un respetable $30,66 \%$. El cargo de vicepresidente estaba más abierto a estos últimos grupos: cerca de la mitad de ellos eran propietarios urbanos o rurales, comerciantes o industriales (el $46,37 \%$ ), mientras que los profesionales de formación universitaria han bajado hasta el $31,88 \%$. La tendencia se confirma entre los dirigentes que ocupaban cargos distintos de la presidencia y la vicepresidencia: sólo uno de cada cuatro es universitario $(26,17 \%)$ mientras que el $45,65 \%$ se encuadra dentro de las fuerzas vivas de la economía urbana y campesina, y ello a pesar de la costumbre de ceder el puesto de secretario a una persona con titulación académica. El estudio de los simples vocales, por último, refuerza plenamente nuestras conclusiones: el $61,63 \%$ de ellos son mesócratas que no han pasado por las aulas universitarias, mientras sólo un 12, 47\% lo han hecho. Como es de suponer, obreros y campesinos, aunque, como hemos observado, están presentes entre los afiliados al progresismo, rara vez consiguen situar a uno de los suyos en cargos de responsabilidad po-

AHNS, Político-Social, Madrid, carpeta 625, legajo 861; carpeta 1897; carpeta 627, legajos 869,870 y 871 ; carpeta 1935 , legajo 862 , y carpeta 1917 , legajo $862 / 3$. 
lítica en los partidos que lo integran, siquiera sea en los muy modestos de las ciudades y pueblos.

Los estratos dirigentes provinciales no nos son, por desgracia, tan bien conocidos, pues las fuentes con las que hemos contado para analizar su extracción socio-profesional son muchos más pobres ${ }^{72}$. Aún así, cabe señalar que la tendencia al predominio de los profesionales de formación universitaria que detectábamos entre los dirigentes locales se acentúa notablemente en los Comités Provinciales: la totalidad de los Presidentes, el $75 \%$ de los Vicepresidentes y un $37,5 \%$ de los Secretarios y demás cargos provinciales del partido han pasado por la Universidad.

En cuanto a la extracción socio-profesional de los dirigentes del PRP en los niveles superiores de su organización (Comités Ejecutivos, Consejos Nacionales, Grupos Parlamentarios) no cabe sino señalar que en ellos culmina la tendencia al predominio de los profesionales de formación universitaria, pues lo son la práctica totalidad, ganando además un predominio indiscutible juristas y abogados, seguidos a alguna distancia por los médicos. $Y$ en lo que se refiere al grupo parlamentario, la tendencia se confirma plenamente: más de la mitad de los diputados de la DLR al principio del primer bienio eran profesionales del derecho, seguidos a gran distancia por los medios, que suponían un poco menos del veinte por ciento, y los catedráticos, que no llegaban al quince ${ }^{73}$. Estas medias superan en mucho las correspondientes al conjunto de las Cortes y, desde luego, a las que caracterizaban a otros partidos republicanos, como el Radical, el más parecido a la DLR, en que suponían los abogados el $40,7 \%$ de la Minoría parlamentaria de $1931^{74}$, Acción Republicana (25\% de abogados frente al $36 \%$ de catedráticos y profesores), o el PRRS $(42 \% \text { frente al } 7 \%)^{75}$.

Parece, pues, que el PRP era sobre todo un partido de clases medias. Pero cosa distinta es afirmar que lograra una gran implantación entre esas clases medias a las que pretendió representar. Desentrañar hasta qué punto lo fue nos lleva a analizar el grado de implantación que alcanzó. Sobre este aspecto, hay que decir que lo parecía haber sido un prometedor inicio, marcado por la fundación acelerada de Co-

\footnotetext{
72 Se trata de los mismos documentos que hemos utilizado para el análisis de los dirigentes locales (ver nota anterior), pero la información que contienen relativa a los Comités provinciale es mucho más escasa.

El Sol, 21 de julio de 1931

74 Ruiz Manjon, O.: El Partido Republicano Radical, 1908-1936. Madrid, Tebas, 1976, p. 594.

Avilés, J.: La izquierda burguesa en la ll República. Madrid, Espasa-Calpe, 1985, p. 345.
} 
mités locales por todo el país y una considerable presentación de candidatos a las elecciones a Cortes Constituyentes, recibió muy pronto el jarro de agua fría de los resultados electorales, que parece que provocan deserciones masivas en favor de otras fuerzas más capaces de proporcionar réditos a los conversos de última hora al republicanismo. La referencia más antigua con que contamos respecto a su grado de implantación nacional maurista, el diputado Juan Castrillo afirma que el PRP «...tiene en España mil cuatrocientos comités, que a un promedio de doscientos afiliados representan mucha fuerza..." ${ }^{76}$. Esto significaría una masa de afiliados cercana a las 280.000 personas, cifra que parece a todas luces propagandística. $Y$ aún suponiendo que fuera cierta, los efectos que sobre ella produjo la escisión maurista hubieron de ser terribles, pues pocas semanas después, en la Segunda Asamblea Nacional del PRP, celebrada en febrero y marzo de 1932, se declaraba a la prensa la presencia de quinientos ochenta y siete comités representados, lo que habría supuesto una pérdida superior a la mitad de los teóricamente existían dos meses antes. Esta marcha descendente de una intervención parlamentaria de Juan Castrillo, anotaba Azaña en su Diario: “El actual Partido Progresista cabe en un taxi» ${ }^{77}$. Meses después, en enero de 1934, la situación empeoraba aún más. La dimisión de César Juarros y la elevación de Cirilo del Río a la jefatura del progresismo debieron de producir una oleada de deserciones, dando un verdadero golpe de gracia a un partido que no era ya más que la sombra de lo que había sido. En Madrid, por ejemplo, la sede central fue abandonada, trasladándose la Secretaría General nada menos que a los locales del Comité del Distrito de Chamberi-Hospicio, con quien habría de compartir instalaciones desde entonces ${ }^{78}$. Pero la crisis mayor se estaba produciendo en Galicia, donde la organización progresista, como apuntábamos más arriba, desertó en bloque, acaudillada por Álvarez Neyra, para constituirse en partido independiente ${ }^{79}$. Debe de ser cierta, en consecuencia, la imagen que ofrecía del progresismo el diario Ahora en esos primeros meses de 1934. Apenas 56.000 afiliados, de los que la inmensa mayoría corresponden a la provincia de Córdoba, patria chica de Alcalá Zamora, seguida a mucha distancia por Valencia, Ávila,

$76 \quad$ Luz, 13 de enero de 1932.

77 Azaña, Manuel: Diarios, 1932-1933. "Los cuadernos robados". Barcelona, 1997, p. 256.

78 Acta del Comité Ejecutivo Nacional de 23 de enero de 1934 (AHNS, Político-Social, Madrid, carpeta 627 , legajo 871). En esa misma reunión se lee la dimisión de Juarros y se elige para sustituirle a Cirilo del Río.

79 Carta al Comité Ejecutivo Nacional fechada en marzo de 1934 (AHNS. Político-Social, Madrid, carpeta 1897). 
Melilla y Salamanca ${ }^{80}$. $Y$ esta imagen se agrava cuando se conocen datos sobre la que sería la última Asamblea Nacional del PRP, la cuarta, que se celebró en el mes de abril. Esta Asamblea se reunió en un local tan reducido como era la sede de la Secretaría General, recientemente trasladada, y a ella asistieron representantes de tan sólo 158 Comités locales, correspondientes a las provincias de Valencia (41 comités), Jaén (22), Salamanca (21), Córdoba (18), Ávila (12), Madrid (también 12, porque los subcomités de Distrito estuvieron representados) y, ya con representación puramente testimonial, Alicante, Cádiz, Ciudad Real, León, Lugo, Melilla, Sevilla, Toledo, Valladolid y Zaragoza ${ }^{81}$. Lista, como vemos, reducida que se encogería aún más con el correr del tiempo. En junio, Garcia Rodrigo, en el transcurso de una intervención ante el Comité Ejecutivo Nacional del partido en la que plantea la urgente necesidad de su reorganización, indica cuál es su estado en esos momentos ${ }^{82}$. Sólo poseen comités progresistas, según sus palabras, las provincias de Valencia, Salamanca, Sevilla, Córdoba, Cádiz, Zaragoza, Ávila, Jaén, Ciudad Real, León, Toledo y Madrid, a las que hay que sumar la ciudad de Melilla. En suma, parece que el prometedor ensayo republicano conservador que venía a encarnar la Derecha Liberal Republicana entre 1930 y 1931 tardó bien poco en convertirse en poco más que unos restos dispersos y mal organizados que sólo sobreviven gracias al padrinazgo externo del Presidente de la República.

Sin embargo, los datos más completos y objetivos a los que podemos recurrir para comprobar la veracidad de estas conclusiones han de provenir necesariamente del análisis de los procesos electorales, y ello en dos aspectos fundamentales: el número y la extensión de las candidaturas presentadas y los resultados cosechados. Si tomamos como referencia los comicios de 1931, los mejores en ambos aspectos para la DLR, aparenta este partido contar con una fuerza considerable. Los candidatos presentados fueron $115^{83}$, que se repartieron entre cuarenta y cuatro de las sesenta y tres circunscripciones. Pero un examen más detenido revela vacíos muy significativos. Así, de las once grandes ciudades a las

80 “Un examen minucioso ...", Ahora, 16 de febrero de 1934.

81 AHNS, Politico-Social, Madrid, carpeta 1897

82 Acta de 9 de junio de 1934, AHNS, Político-Social, Madrid, carpeta 627, legajo 871

83 Según un documento hallado en al Archivo Histórico Nacional de Madrid, la "derecha republicana" presentó en las elecciones de junio de 1931 un total de 124 candidatos en sesenta y tres circunscripciones ( Ministerio de Gobernación, Sección de Orden Público. Proclamación de candidatos de diputados a Cortes Constituyentes", AHNM, Ministerio del Intenior, Serie A, Legajo 31). No obstante, no todos los candidatos recogidos pertenecen al partido. Realmente, DLR debió de presentar unos 115 . 
que los decretos por los que se regían las elecciones habían concedido circunscripción propia, sólo en cuatro - Madrid, Valencia, Zaragoza y Cartagena - presentaba candidatos el partido de don Niceto. En segundo lugar, toda una zona del país, quizá la de mayor densidad demográfica y más sólido desarrollo industrial —el País Vasco, Navarra y la mayor parte de Cataluña - carece de candidaturas de la DLR. Por último, resulta evidente el predominio de éstas en el sur del país, y más concretamente, de aquellas circunscripciones en que suponen un número equivalente a la mitad o más de los puestos en juego, cuando es precisamente esta zona donde la vigencia de los mecanismos de tipo clientelar conserva aún una cierta vigencia ${ }^{84}$.

El análisis de los resultados ayuda a matizar aún más la visión de la DLR como un partido de implantación nacional. Se plantea aquí, no obstante, el problema de la complejidad del sistema electoral vigente durante la Segunda República, mayoritario a doble vuelta, con sufragio limitado y listas abiertas. En un sistema así, los electores daban su voto a personas, no a partidos, lo que hace muy difícil valorar con exactitud cuál era el apoyo con el que estos contaban efectivamente. Si hay algo claro, sin embargo, es que con una ley electoral de esta índole, no es el número de escaños cosechados el indicador que mejor muestra la implantación de un partido, sino el volumen de los votos que obtiene. Aceptado esto, tampoco deja de ser dificil cuantificar con exactitud los sufragios, pues cada elector emite tantos votos como candidatos se le permita seleccionar en su circunscripcion.

De los diversos sistemas posibles para medir ese apoyo, consideramos que el que mejor sirve a nuestros fines es el denominado indice de Apoyo Popular (IAP), que ha sido ya utilizado con anterioridad por algunos autores ${ }^{85}$ y relaciona para cada circunscripción los votos logrados por los candidatos del partido o tendencia en cuestión con el número total de escaños que elige esa circunscripción y el censo de electores que tienen derecho a emitir su voto en ella, de acuerdo con la siguiente fórmula:

$$
I A P=100(V / M) / E
$$

84 Los datos han sido extraidos de TUSELL, J. : Las constiluyentes de 1931: unas elecciones de transición. Madrid, CIS, 1982, passim, y de una serie de estudios monográficos relativos a las distintas regiones y provincias.

85 Por ejemplo Juan AVILÉS, que se vale de él en su estudio sobre la izquierda burguesa en la Segunda República (p. 286 y ss.), o William J. IRWIN, quien lo ha usado en su monografia sobre las elecciones generales de 1933 (Vid. IRWIN, William J.: The 1933 Cortes Elections. Origin of the Bienio Negro.Garland Publishing, Nueva York y Londres, 1991, Preface, p. XIV.) 
Donde $V$ es el número de votos recibidos en la circunscripción por todos los candidatos del partido o tendencia; $\mathrm{M}$, el número de escaños que se eligen en ella, y E, su censo electoral.

Pues bien, si aplicamos dicho índice a los comicios de 1931, observando que sólo en cinco provincias - Cuenca, Palencia, Toledo, Jaén y Soria- supera el partido un I A P del diez por ciento, pero dado que en los tres primeros casos se beneficiaron sus candidatos de su inclusión en las listas de la Conjunción republicano-socialista, cabria concluir que únicamente lograron un apoyo popular significativo en Jaén y Soria, feudo tradicional de Alcalá-Zamora la primera y de Gregorio Arranz Olalla, significado seguidor de Miguel Maura, la segunda. El análisis de un segundo nivel de apoyo, el marcado por un IAP entre el 5 y el $10 \%$, no resulta menos concluyente. En el se enmarcan un número importante de provincias de la España levantina y meridional, así como Aragón y la zona occidental de Castilla la Vieja y León, zonas en general de exiguo desarrollo urbano e industrial, más proclives en consecuencia a la persistencia de formas tradicionales de movilización política. Si a ello sumamos, de nuevo, la práctica carencia de votaciones significativas en Cataluña, Pais Vasco, Navarra, las comarcas más urbanizadas de Galicia y la mayoría de las grandes ciu-

\section{I.A.P. de la Derecha Liberal Republicana (1931)}

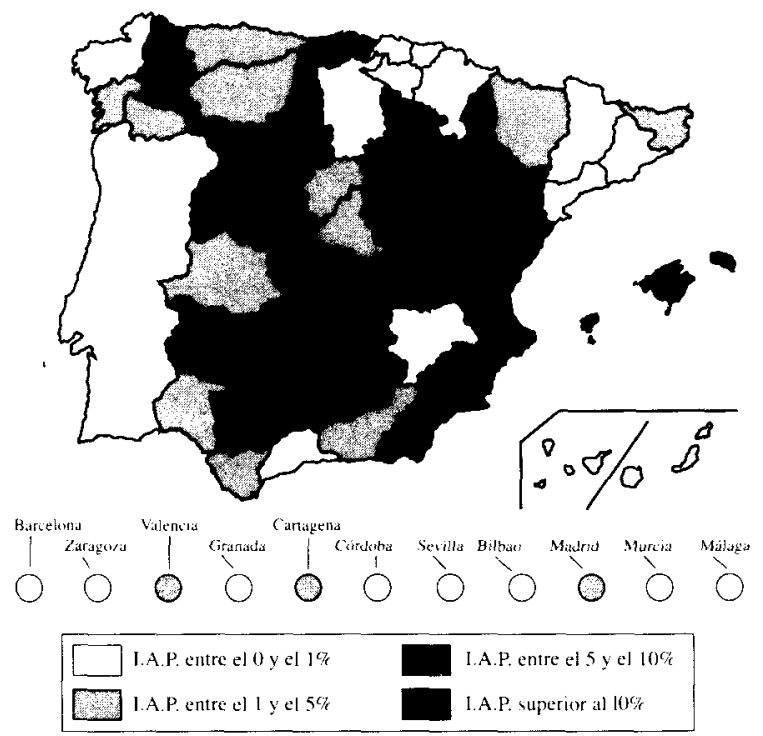

(Elaboración propia, sobre datos de TUSELL, J.: Las Constituciones..., pp. 161-196, y otros). 
dades, la imagen que obtenemos es la de un partido que no ha sido capaz de adaptarse a las exigencias políticas de una sociedad en tránsito hacia formas más modernas de movilización de la opinión. Huelga, por supuesto, añadir nada sobre los comicios posteriores, en los que la deserción en masa de los seguidores de Miguel Maura para integrarse en el Partido Republicano Conservador dejó al ahora denominado Partido Republicano Progresista en una situación marginal, al borde de una extinción a la que sólo pudo sustraerse gracias a la presencia en la presidencia de la República de su fundador, cuyas intervenciones en la formación de los sucesivos gobiernos le permitieron contar en ellos con una representación a la que nunca habría podido aspirar en función de su peso político real. Si la misión con la que había venido al mundo en 1930 la DLR era movilizar a las clases medias de orden en sustento de una República conservadora, no cabe sino concluir que su fracaso había sido absoluto.

\section{UNA MODERNIDAD SÓLO APARENTE}

Basándonos en fuentes oficiales, hemos visto, al abordar la descripción formal de la estructura organizativa del progresismo, que, en apariencia y en intención al menos, nos encontramos ante un partido que intenta sinceramente incorporarse a los usos y costumbres políticos de la democracia de masas. De la lectura de sus reglamentos se deduce que su organización ejercía un control considerable sobre sus afiliados. Tamizaba su admisión, imponiéndoles en ocasiones el requisito de ser presentados por militantes de probada lealtad. Se aseguraba de arrancar de ellos el acatamiento a las ideas y la disciplina del partido. Registraba con detalle sus derechos y obligaciones, cargándoles con el pago de cuotas regulares, y no se olvidaba de entregarles un carnet para fortalecer su sentido de pertenencia a la comunidad de sentimientos y fines que el partido pretendía constituir.

No en menor grado impresiona también el grado de democracia y participación de que esta organización hacía gala, sobre todo en los procesos electorales. Si las elecciones eran de ámbito nacional, los afiliados podían escoger, aunque con una cierta supervisión de los órganos centrales, a los candidatos que deseaban que su partido presentara a los comicios. $Y$ cuando las elecciones eran municipales, los organismos superiores no intervenían en absoluto ${ }^{86}$. Además, los militantes de base elegian mediante el voto a

86 Una carta remitida por el Presidente del Comité local de Valencia de Mombuey a la Secretaria General el 24 de mayo de 1931 informaba de la elección por la agrupación que dirigía de los can- 
sus delegados en las Asambleas Nacionales anuales, órganos soberanos de la DLR-PRP, tenían derecho a proponer, a través de sus comités locales, asuntos que eran incluidos en el orden del dia de las mismas, e incluso poseían el derecho a intervenir directamente en ellas.

Las agrupaciones locales parecían, además, conscientes del grado de autonomía que sus estatutos, que ellas mismas habían aprobado, les garantizaban para todo lo relativo al ámbito local y comarcal, y en ocasiones llegaban a defenderlo con firmeza frente a posibles intrusiones de los organismos madrileños. Así sucedió, por ejemplo, en octubre de 1932, cuando el Comité local cordobés del PRP decidió por unanimidad proclamarse único organismo competente para juzgar la conducta de uno de los concejales del partido en el Ayuntamiento de la ciudad, que, en su opinión, había sido injustamente inculpado y expulsado de las filas progresistas. El acta de la reunión recoge también la protesta unánime de sus integrantes ante el Comité Nacional, al que acusan de extralimitarse en sus funciones al aceptar la culpabilidad del concejal sin haber oído antes al Comité Local, y declaran sin valor alguno la expulsión de Baquerizo, que asi se llamaba el edil en cuestión ${ }^{87}$.

No debemos, sin embargo, llamarnos a engaño. Ya hemos señalado algunos aspectos en los que la realidad del progresismo no era ni tan moderna ni tan democrática como aparentaba. La financiación, por ejemplo, provenia de fuentes bien distintas de las cuotas de los afiliados, exiguas en la cantidad y erráticas en la regularidad con que afluían a las arcas del partido. La autonomía de las secciones que acompañaban su nombre con tal calificativo - Juventudes, Sección Femenina- no pasaba de aquellas actividades políticamente inocuas que, como los concursos de parchis o la recogida de juguetes para los niños pobres, poco podían interesar a los Comités locales y provinciales. La implantación social y geográfica del partido, por último, no pasaba de algunas regiones muy limitadas y concretas que, no siendo de las más avanzadas económica y socialmente, parecen demasiado susceptibles de soportar aún un clientelismo político cuya probabilidad pesa como una losa sobre su supuesta modernidad.

\footnotetext{
didatos para las elecciones municipales de inminente celebración, y, lo que es más elocuente, decía haber comunicado ya los nombres de los aspirantes al Gobernador Civil (AHNS, Político-Social, Madrid, carpeta 615, legajo 869). Del mismo modo, un aviso publicado en el periódico alcoyano Democracia el 28 de marzo de 1931 convocaba a todos los afiliados a la DLR en la localidad a una asamblea general para «...elegir a los candidatos que en representación de nuestro partido han de integrar la candidatura Republicano-Socialista que ha de votarse en las próximas elecciones municipales".

${ }_{87}$ Acta del Comité local de Córdoba, 1 de octubre de 1932 (AHNS, Político-Social, Madrid, carpeta 1897).
} 
Si analizamos con algún detalle el funcionamiento del órgano soberano del partido, la Asamblea Nacional, elemento clave para valorar el grado de democracia real con el que funcionaba, llegamos a conclusiones aún más concluyentes. Llama la atención, para empezar, el mecanismo real que se utilizaba para la elección de los delegados en dichas Asambleas. Cada Comité local debía escoger a uno o varios miembros del partido para que lo representaran en Madrid y su libertad para ello era absoluta. En la práctica, decenas de Comités de la misma región o provincia seleccionan sistemáticamente a una misma persona, que, elocuentemente, suele ser el prohombre del partido en la circunscripción ${ }^{88}$, y ello a pesar de que, al menos al principio, se había intentado limitar a cinco el número de representaciones que un sólo delegado podía acumular ${ }^{89}$. Parece, por tanto, cobrar fuerza la imagen que antes apuntábamos de un partido compuesto por la suma de múltiples influencias locales de tipo clientelar, aunque esta tendencia al refuerzo de mecanismos oligárquicos, como ya demostrara Michels, no sea exclusiva de los partidos burgueses de cuadros y a menudo se refuerce, en lugar de atenuarse, a la vez que se perfecciona la organización ${ }^{90}$.

Otras prácticas fomentaban la tendencia a que fueran siempre un pequeño número de prohombres regionales los que tomaban las grandes decisiones. Lo habitual es que no sólo los delegados de los Comités, sino también personas que no representaban a las bases del partido como tales tuvieran voz y voto. Tal era el caso de los integrantes de la Minoría parlamentaria, altos cargos de la Administración estatal, ex-Gobernadores civiles y candidatos en los procesos electorales que hubieran cosechado más de mil votos ${ }^{91}$. En apariencia, se incrementa la representatividad de la Asamblea, pero en la práctica se da mucho peso a un colectivo muy limitado extraído de las capas dirigentes del partido a nivel nacional, que, al añadirse a un número exiguo de repre-

88 Hemos podido consultar decenas de actas de Comités locales que confirman que esta práctica debía de ser bastante habitual. Así, en Ávila, diez de los doce Comités representados en la Cuarta Asamblea Nacional habian elegido como representante a San Román; todos los gaditanos habian escogido a Manuel Rodrigo, y veintiuna de las veintidós agrupaciones jienenses se habian pronunciado por Miguel Pastor (AHNS, Politico-Social, Madrid, carpeta 1897).

89 Circular de la Secretaria General del PRP de 21 de diciembre de 1931 (AHNS, Político-Social, Madrid, carpeta 630 , legajo 873 ).

90 Michels señala cómo “En la vida de los partidos democráticos modernos podemos observar signos de (...) indiferencia. Sólo una minoría participa de las decisiones partidarias, y a veces esa minoría es de una pequeñez rayana en to ridiculo. Las resoluciones más importantes adoptadas por el más democrático de todos los partidos - el partido socialista- emanan siempre de un puñado de sus miembros. Es verdad que la renuncia al ejercicio de los derechos democráticos es voluntaria (MicheLS, Robert : Los partidos..., I, p. 95).

91 Circular de la Secretaria General del PRP de 21 de diciembre de 1931 (AHNS, Político- Social, Madrid, carpeta 630, legajo 873). 
sentantes de Comités locales ya a su vez manipulado en un sentido oligárquico por la tendencia a la inhibición de las bases, no hace sino reforzar al máximo el carácter minoritario del proceso de toma de decisiones.

Un factor añadido puede actuar como refuerzo último de dicha tendencia: la deficiente organización de las Asambleas, cuyo reglamento queda con frecuencia incumplido en algunos aspectos clave, como es la verificación de la autenticidad de las representaciones de los delegados. En teoria, el mecanismo de control era impecable. Una circular remitida semanas antes de la Asamblea a los Comités locales les recordaba que para que sus representantes fueran aceptados como tales debían presentarse con una tarjeta de asambleista expedída por la Secretaría General del partido. Este documento sólo se concedería a los delegados de aquellos Comités que hubiesen remitido a tiempo a Madrid copia del acta de la elección, exigencia a la que llegó a añadírse en la Cuarta Asamblea la de registrar en la Secretaria una certificación del acta de su constitución y existencia efectiva como Comités ${ }^{92}$. Tanta exigencia, que sólo cabe entender como un intento de detener el alcance de un fraude generalizado, a menudo no pasaba de la pura teoría, pues llegado el momento de examinar la validez de las credenciales, era tan alto el número de las que incumplían algún requisito, que las Asambleas no hubiesen podido celebrarse de haberse exigido el cumplimiento puntual del reglamento ${ }^{93}$. El resultado es que a menudo las Asambleas dejaban mucho que desear en su representatividad real. Muchos Comités no existian realmente o estaban compuestos por dos o tres personas. Los prohombres provinciales que decian llevar decenas de representaciones, y contaban por ello con un poder de voto proporcional, no podían responder a mandatos concretos que no tenían y contaban con total libertad para imponer sus opiniones sin responder luego ante nadie.

Y esa posibilidad que les venía ya facilitada desde las bases se fortalecía gracias a los usos y costumbres que se hallaban plenamente consolidados en la práctica de las Asambleas. La aquiescencia de los delegados

92 Circulares de 15 de junio de 1933 (AHNS, Político-Social, Madrid, carpeta 1897, y La Defensa, 5 de julio de 1933) y de 15 de marzo de 1934 (AHNS, Político-Social, Madrid, carpeta 1897).

93 Véase el informe de fecha 17 de abril de 1934 de la Comisión Dictaminadora de Actas de la Cuarta Asamblea Nacional del PRP en AHNS, Político-Social, Madrid, carpeta 1897. En la Tercera Asamblea, la mesa interina, compuesta elocuentemente por el Comité Ejecutivo Nacional del partido, decidió sin más dar por válidas todas las representaciones a pesar de las graves deficiencias que presentaban la mayoria de ellas (Actas de la Asamblea en AHNS, P-S, Madrid, carpeta 627, legajo 870). En la Cuarta, la Comisión Dictaminadora aconsejó constituir la Asamblea con las actas limpias de forma provisional, pero ignoramos qué se hizo en realidad. 
de los Comités a las iniciativas de los órganos centrales se asegura mediante el escasamente sutil mecanismo de obligarles a presentarse en la Asamblea sin conocer con detalle lo que se va a tratar en ésta, pues con frecuencia no se cumple la obligación reglamentarla de remitir el orden del día a las agrupaciones de todo el país con antelación suficiente para que éstas lo discutan y puedan enviar a sus delegados con un mandato de voto. Por supuesto, jamás se presentan listas alternativas a la oficial para la elección de los órganos centrales de gobierno y las votaciones se realizan a menudo por aclamación, cosechando automáticos abucheos cualquier proposición que se expresara en el sentido de pedir votaciones nominales, y en ocasiones sobre documentos que ni siquiera se han leído previamente. La palabra del Presidente es incuestionable y se considera poco menos que una traición al partido cualquier crítica que se exprese sobre sus posiciones, que son siempre las que aquél asume como oficiales ${ }^{94}$. Con frecuencia, cuando las discusiones se prolongan en exceso o comienzan a manifestarse discrepancias, por lo general de matiz, la discusión se zanja sin más mediante recurso tan poco sutil como el de otorgar un voto de confianza a la mesa o al Presidente del partido, para que solucionen el asunto según su buen criterio. La sobrecarga carismática y el exceso de personalismo vienen así a sumarse a las tendencias oligárquicas para configurar to que ha de ser la imagen real del progresismo más allá de lo que dicen sus estatutos.

La distancia entre la teoría democrática y la práctica oligárquica que caracterizaba al PRP se aprecia de forma no menos evidente en los mecanismos que solian aplicarse para la selección de los candidatos que habian de presentarse en los distintos procesos electorales. También en un asunto tan delicado como éste la tendencia a la inhibición de las bases y de los mismos delegados que las representan en algunas etapas del proceso de toma de decisiones facilita que vengan a ser casi siempre los dirigentes, mediante el tradicional mecanismo de los votos de confianza para..., los que acaben decidiendo quiénes aspirarán al desempeño de

94 La Primera Asamblea Nacional de la Derecha Liberal Republicana fue paradigmática en este aspecto. Alcalá Zamora la dirigió en fodo momento sin estar presente de forma física ni un segundo. Lo más elocuente es la forma en que se aprobó el programa del partido. Sánchez Covisa, uno de los dos vicepresidentes de la mesa, dio cuenta de una conversación sostenida la tarde anterior entre los integrantes de la Minoria parlamentaria y el fundador del partido, en la que «...el $\mathrm{Sr}$. Alcalá Zamora expuso algunas ideas, que la minoria ha hecho suyas y que somete al juicio de la Asamblea para que ésta las tome a guisa de inspiración sobre la cual pueda ella tomar determinaciones definifivas acerca del programa que adopte el partido" ( $E /$ Sol, 4 de agosto de 1931). Huelga decir que la Asamblea adoptó dichas ideas por aclamación unánime y entusiasta, en medio de grandes vitores al fundador del partido. 
cargos públicos de designación popular, práctica que convertía en inoperante el derecho teórico de las asambleas provinciales a escoger los candidatos. Naturalmente, esto no sucedía siempre, pues en ocasiones las asambleas ejercian su derecho y escogían los candidatos que se presentarían en su circunscripción, aunque siempre con la aprobación del Comité Nacional. Pero incluso cuando ocurría esto, la elección recaía en los notables regionales; los mismos que, dueños de una gran influencia previa a la existencia misma de la Derecha Liberal Republicana, habian sido responsables de su fundación en su provincia ${ }^{95}$, los mismos que los controlaban día a día; los mismos que resultaban elegidos asamblea tras asamblea para representar a las bases; los que copaban los cargos de dirección en Madrid y se sentaban en los escasos escaños que se obtenían en las Cortes. La práctica tendía a configurar así a este partido como un entramado de influencias personales de mayor o menor entidad cuyo equilibrio determinaba su política interna. El líder, como es lógico, dirigía esta coalición en tanto que en él confluian la cualidad de notable regional, dueño de una influencia política propia en un área o áreas concretas, y un carisma de alcance nacional, más difuso, pero capaz también de cosechar votos ${ }^{96}$.

Parece, como conclusión, que la Derecha Liberal Republicana, luego Partido Republicano Progresista, se hallaba poco preparada desde el punto de vista organizativo para enfrentarse a las exigencias de la era de la política de masas, en cuyos albores se encontraba la España de los años treinta, como bien ha señalado Tusell ${ }^{97}$. Puede reconocerse que al menos intentó adaptarse, pero lo hizo con voluntad más bien escasa y

\footnotetext{
95 Las fichas de afiliación a la OLR resultan reveladoras en este sentido. Cuando el afiliado es una persona influyente, capaz de movilizar apoyos de alguna importancia en favor del partido en ciernes, se refleja en el dorso de la ficha. Habitualmente, esa persona es después encargada de la organización de la red de Comités locales y, de forma provisional, del Provincial mismo en su demarcación. Asi sucede con figuras como Juan Bautista Catalá en Alicante o Agustín García de Diego en Ávila, como queda reflejado en incontables cartas que la Secretaria General recibia de estos personajes dando cuenta de sus actividades (AHNS, Politico-Social, Madrid, carpeta 627, legajo 871). En ocasiones, tales prácticas provocaban el disgusto de algunos afiliados que se incorporaban al partido creyéndolo democrático o bien se sentian defraudados en sus expectativas de medro personal, como le sucedió a Cristóbal Amorós, un abogado residente en Villena (Alicante), que protestó de un hecho tan escandaloso como elocuente: "...que se haya designado jefe provincial a un señor, sin haberse consultado a los afiliados y sin aguardar a que el partido estuviera constituido en diversos pueblos" (Carta de Cristóbal Amorós Cerdán a Manuel García Rodrigo, 22 de noviembre de 1930, AHNS, P-S, Madrid, carpeta 625, legajo 869).

96 Para un mayor desarrollo del concepto coalición dominante, véase Panebianco, A. : Modelos ... pp. 321 y ss.

97 TUSELL, Javier : Las Constituyentes de 1931: unas elecciones de transición. Madrid, CIS, 1982. Passim.
} 
desigual constancia. Sin duda sus dirigentes, la mayoría de ellos formados en la era de la política de notables, comprendieron que algunas cosas habían cambiado con la llegada de la República. Entendieron la necesidad de contar con una organización que se extendiera por todo el país; con órganos de prensa capaces de hacer llegar su mensaje a los electores; incluso con estructuras especializadas capaces de movilizar y agrupar a sectores decisivos de la sociedad, como los jóvenes o la mujer. Asumieron, en otras palabras, que la política se hacía ya más en la calle, en los estadios y en los teatros que en los círculos y gabinetes, porque hacer política ahora era ante todo conquistar el apoyo de la opinión pública. Pero, prisioneros un tanto de sus orígenes, cargados con la masa inerte de quienes ya les seguían, no pudieron o no supieron librarse de ella y comenzaron a construir una fuerza política, en teoría nueva, sobre lo que ya tenían, todo ello propio y característico de la era de la política de cuadros: un cierto prestigio a nivel nacional, fruto de sus luchas pasadas o recientes influencias de tipo clientelar en los distritos que antaño les votaban; notables de segunda fila adictos a su persona más que a unas ideas escasamente articuladas... Pero no fueron capaces de dotar a su partido de fuentes seguras de financiación que les proporcionaran los medios para competir en el terreno en el que ya tantos votos se decidían, el de la propaganda; ni de desarrollar una organización que se extendiera por todas las provincias y núcleos de población importantes. Tampoco otorgaron participación real a sus escasos afiliados, convertidos las más de las veces en comparsas de sus siempre infalibles líderes, lo que cerraba el camino hacia toda posible renovación real del partido, que quedaba así condenado a la marginalidad o a la satelización.

El primero de estos destinos fue el que correspondió al Partido Republicano Progresista, que, casi desmantelado tras la escisión maurista, vegetó en la miseria de sus tres escaños parlamentarios durante todo el segundo bienio. Su presencia casi continua en el Gobierno durante esos dos años no debe llamar a engaño. Sólo el hecho de que su fundador fuera en ese tiempo Presidente de la República y, por supuesto, nunca hubiera dejado de dirigir de algún modo el partido desde fuera, explica que una fuerza tan marginal pudiese contar de manera continuada con un ministro en el gabinete y, en alguna ocasión, incluso con dos. Es cierto que en este desgraciado destino quizá tuvieron también importancia los factores ideológicos, pues no es descabellado preguntarse si había espacio en la sociedad española de los años treinta para una opción a la vez republicana - esto es, democrática - y conservadora y laica, como la que pretendía abanderar la DLR. Responder a esta cuestión trasciende, sin embargo, los fines de este trabajo. 